\title{
MOLECULAR ABUNDANCES AND LOW-MASS STAR FORMATION. II. ORGANIC AND DEUTERATED SPECIES TOWARD IRAS 16293-2422
}

\author{
Ewine F. van Dishoeck, ${ }^{1}$ Geoffrey A. Blake, ${ }^{2}$ David J. Jansen, ${ }^{1}$ AND T. D. Groesbeck ${ }^{3}$ \\ Received 1994 September 15; accepted 1995 January 20
}

\begin{abstract}
Millimeter and submillimeter line surveys of the protobinary source IRAS 16293-2422 are presented in the 230 and $345 \mathrm{GHz}$ windows. In total, 265 lines belonging to 44 molecules and their isotopomers $(24$ chemically different species) have been detected. Here the data for organic and deuterated molecules are considered; the results for Si- and S-bearing species have been discussed in an earlier paper (Blake et al. 1994). The observations have been analyzed through a combination of rotation diagrams and full statistical equilibrium/ radiative transfer calculations. At least three physically and chemically different components can be distinguished within the $20^{\prime \prime}(3000 \mathrm{AU})$ beam. The first component is the warm $\left(T_{\text {kin }} \gtrsim 80 \mathrm{~K}\right)$ and dense $\left[n\left(\mathrm{H}_{2}\right) \approx(0.5-1) \times 10^{7} \mathrm{~cm}^{-3}\right]$ gas sampled by $\mathrm{Si}$ - and $\mathrm{S}$-containing molecules such as $\mathrm{SiO}$ and $\mathrm{SO}_{2}$. This gas is found to be rich in organic molecules such as $\mathrm{CH}_{3} \mathrm{OH}, \mathrm{CH}_{3} \mathrm{CN}$, and $\mathrm{H}_{2} \mathrm{CO}$, as well. It is only $3^{\prime \prime}-10^{\prime \prime}$ in size (500-1500 AU) and most likely represents the interaction of the bipolar outflow(s) with the circumbinary envelope. The second component is the circumbinary envelope itself, which has $T_{\text {kin }} \approx 40 \mathrm{~K}$ and $n\left(\mathrm{H}_{2}\right) \approx$ $10^{6}-10^{7} \mathrm{~cm}^{-3}$ and is $10^{\prime \prime}-15^{\prime \prime}$ in size (2000 AU). It contains common molecules like CS, $\mathrm{HCO}^{+}$, and $\mathrm{H}_{2} \mathrm{CO}$. The third component is the colder, lower density outer part of the envelope, which gradually fades into the ambient surrounding cloud core $\left[T_{\text {kin }} \approx 10-20 \mathrm{~K} ; n\left(\mathrm{H}_{2}\right) \approx\left(3 \times 10^{4}\right)-\left(2 \times 10^{5}\right) \mathrm{cm}^{-3}\right]$. Radicals such as $\mathrm{CN}$, $\mathrm{C}_{2} \mathrm{H}$, and $\mathrm{C}_{3} \mathrm{H}_{2}$ appear to reside principally in this region. The ambient cloud material is also probed through self-absorbed features in the line profiles of molecules such as $\mathrm{HCN}, \mathrm{HCO}^{+}$, and $\mathrm{H}_{2} \mathrm{CO}$. Beam-averaged abundances over a $20^{\prime \prime}$ scale are presented and are compared with those observed in cold dark clouds such as L134N and TMC-1 and with high-mass star-forming cores such as Orion-KL. Remarkably high deuterium fractionation ratios are found, which are more characteristic of hot core regions than of cold, quiescent clouds. As a whole, the chemical and physical regimes that can be distinguished in the low-mass young stellar object IRAS $16293-2422$ are qualitatively similar to those found in high-mass star-forming regions, confirming the earlier conclusion that the chemical composition depends more on the age of the object than its mass.
\end{abstract}

Subject headings: circumstellar matter - ISM: molecules - stars: individual (IRAS 16293-2422) stars: pre-main-sequence

\section{INTRODUCTION}

A detailed understanding of the chemical composition of young stellar objects (YSOs) is of interest not only for its own sake, but also because of the information molecules may provide about the physical and chemical evolution during the star formation process. The potential of molecules as probes of physical parameters such as temperature and density has been exploited for many years using millimeter-wave data in molecular clouds (e.g., Evans 1980; Goldsmith 1984; Walmsley 1987; Genzel 1992). With the advent of large-aperture submillimeter telescopes equipped with sensitive high-frequency receivers, it is now possible to also apply these techniques to the earliest, densest, most embedded phase of star formation. The significance of molecules as chemical diagnostics has been realized only more recently. Although chemical variations between molecular clouds (and even within them) have been recognized for quite some time (e.g., Irvine, Goldsmith, \& Hjalmarson 1987; Swade 1989), their origin has remained ill explained. Because the birth of stars is accompanied by known energetic processes such as outflows, chemical changes compared with the parental molecular cloud are bound to occur (Blake et al. 1987; Turner 1988; van Dishoeck et al. 1993a; Hartquist et al.

\footnotetext{
${ }^{1}$ Leiden Observatory, P.O. Box 9513, 2300 RA Leiden, The Netherlands.

2 Division of Geological and Planetary Sciences, 170-25, California Institute of Technology, Pasadena, CA 91125.

${ }^{3}$ Division of Physics, Mathematics, and Astronomy, 405-70, California Institute of Technology, Pasadena, CA 91125.
}

1993a, b). Observations of such distinct chemical signposts may eventually serve as sensitive probes of the timescales associated with the various stages of YSO evolution.

Stimulated by these ideas and by the availability of new observational facilities, we have begun a general survey of the chemistry associated with deeply embedded YSOs, in particular those of lower mass and luminosity. A prime example of an object in this category is IRAS $16293-2422$, a young, extreme class I binary YSO in Ophiuchus with a total system luminosity of only $27 L_{\odot}$ (Walker et al. 1986). Two millimeter dust continuum sources are observed, each with a mass of $\sim 0.5 M_{\odot}$ and a size less than $250 \mathrm{AU}(<1$ ".5; Mundy, Wootten, \& Wilking 1990; Mundy et al. 1994). These sources coincide with two radio continuum sources found at $2.2 \mathrm{~cm}$ by Wootten (1989), with a projected separation of $840 \mathrm{AU}$ at a position angle of $135^{\circ}$. The southeastern of the two sources appears to be more active, as evidenced by its outflow(s) (Walker et al. 1988, 1990; Mizuno et al. 1990) and water maser emission (Wilking \& Claussen 1987; Terebey, Vogel, \& Myers 1992). The two unresolved circumstellar dust sources, likely to be flattened accretion disks feeding the central stars, are surrounded by a larger, dense circumbinary envelope of size $10^{\prime \prime}-20^{\prime \prime}(\sim 1500-3000 \mathrm{AU})$. This envelope, in turn, is embedded in a cold molecular cloud core (Menten et al. 1987; Mundy et al. 1992; Mezger et al. 1992).

We have performed a systematic (sub)millimeter-wave spectra! line survey of IRAS $16293-2422$ in the 230 and $345 \mathrm{GHz}$ 
atmospheric windows using single-dish telescopes. Within the typical 20" beam (2000 AU), various physical regimes are sampled. In an earlier paper (Blake et al. 1994, hereafter Paper I), we have reported on our observations of $\mathrm{Si}$ - and $\mathrm{S}$ containing species. Kinetic temperatures of $T_{\text {kin }} \approx 70-80 \mathrm{~K}$ and densities $n\left(\mathrm{H}_{2}\right) \approx(0.5-1.0) \times 10^{7} \mathrm{~cm}^{-3}$ were derived from the excitation of these molecules. Their abundances were found to reflect the energetic events occurring near the YSO(s). In particular, the refractory $\mathrm{SiO}$ molecule was found to be enhanced as the result of the interaction of the bipolar outflow(s) with the surrounding envelope, resulting in shocks which can sputter and destroy dust grains and return Si to the gas phase (Ziurys, Snell, \& Dickman 1989; Bachiller, MartínPintado, \& Fuente 1991; Martín-Pintado, Bachiller, \& Fuente 1992). Sulfur-bearing molecules were also found to be enhanced, probably as the result of high-temperature (shockinduced) reactions.

In this paper, we present results for the remaining organic and deuterated species, which are expected to sample different physical and chemical regimes. In high-mass star-forming regions such as Orion-KL and W3, organic molecules are very characteristic of chemical processes taking place in "hot cores," in which molecules like $\mathrm{CH}_{3} \mathrm{OH}$ are evaporated off the grains and subsequently form more complex organic molecules such as $\mathrm{CH}_{3} \mathrm{CHO}$ and $\mathrm{CH}_{3} \mathrm{OCH}_{3}$ through gas-phase ionmolecule and neutral-neutral reactions (Blake et al. 1987; Brown, Charnley, \& Millar 1988; Millar, Herbst, \& Charnley 1991; Charnley, Tielens, and Millar 1992; Caselli, Hasegawa, \& Herbst 1993; Millar 1993; Walmsley \& Schilke 1993; Helmich et al. 1994). Deuterated molecules such as DCN, $\mathrm{HDCO}$, and $\mathrm{CH}_{3} \mathrm{OD}$ are found to be enhanced in hot core regions as well (Walmsley et al. 1987; Mauersberger et al. 1988; Mangum, Plambeck, \& Wootten 1991; Turner 1990; Jacq et al. 1990), consistent with models in which highly deuterated molecules are formed in the cold prestellar cores and on the grains during the collapse phase and are subsequently evaporated after the star has formed (Tielens 1989; Brown \& Millar 1989). An important question addressed in this paper is to what extent these characteristics are also found around lowmass YSOs with a factor of 1000 lower luminosities, such as IRAS $16293-2422$. In particular, in high-mass star-forming regions the icy grain mantles can be removed either by shocks or more passively by heating of the grains due to radiation from the newborn star. In low-luminosity objects such as IRAS $16293-2422$, the latter process is thought to be negligible. A similar study has recently been performed for the low-mass object NGC 1333 IRAS 4 by Blake et al. (1995).

In $\$ 2$ and 3 , the observational details and methods of analysis are briefly reiterated, whereas in $\S 4$, the data for the various molecules are interpreted both through rotation diagrams and more detailed statistical equilibrium calculations. Finally in $\S 5$, the inferred physical conditions in the various components are discussed and the derived beam-averaged abundances are compared with those found in cold clouds and warm high-mass star-forming regions. The structure and scope of this paper are similar to those of Paper I. In a subsequent paper, more sophisticated modeling based on the entire data set will be presented.

\section{OBSERVATIONS}

Spectral lines between 200 and $400 \mathrm{GHz}$ were observed with the Caltech Submillimeter Observatory (CSO) ${ }^{4} 10.4 \mathrm{~m}$ and the James Clerk Maxwell Telescope (JCMT) ${ }^{5} 15 \mathrm{~m}$ telescopes located atop Mauna Kea, Hawaii. Details of the receivers, back ends, and beam efficiencies can be found in Paper I. Absolute calibration is accurate to $\sim 30 \%$, but the relative calibration within each data set is expected to be better, $\sim 15 \%$. On-source integration times were typically $15-30$ minutes, resulting in rms antenna temperatures of $20-40 \mathrm{mK}$. Such high sensitivity is essential for detecting the weak features due to optically thin isotopic varieties and to rarer (organic) molecules, which carry the most relevant chemical and physical information.

About $20 \mathrm{GHz}$ was covered in each atmospheric window, with the 239-250 and 338-347 GHz regions scanned nearly completely. A list of the frequency settings and the rms of each setting is available on request. In total, 265 lines due to 44 molecules and their isotopomers (24 chemically different species) were detected. The line crowding in the doublesideband spectra is sufficiently low that the identification of the species is quite secure. Only a handful of unidentified lines were found (see Paper I). The beam size of the JCMT at $230 \mathrm{GHz}$ is $20^{\prime \prime}$, the same as that of the CSO at $345 \mathrm{GHz}$. These values vary slightly within the atmospheric windows, but such changes are generally small compared with the pointing and calibration uncertainties and were not taken into account in the analysis. The matched beam sizes at 230 and $345 \mathrm{GHz}$ are important in the analysis since the derived source sizes for most molecules are of order $\sim 10^{\prime \prime}$, comparable to the beam size (Paper I). The line widths also provide significant information. At the JCMT, the spectral resolution of the acousto-optical spectrometer (AOS) was $\sim 0.3 \mathrm{~km} \mathrm{~s}^{-1}$ at $230 \mathrm{GHz}$, but the frequency instability of the local oscillator resulted in an effective resolution of $\sim 0.6 \mathrm{~km} \mathrm{~s}^{-1}$. At the CSO, the effective spectral resolution of the broadband $500 \mathrm{MHz}$ AOS was more than $1.5 \mathrm{~km} \mathrm{~s}^{-1}$ at 345 GHz. Reliable profiles at this telescope were only obtained for a handful of lines with the 1024 channel, $50 \mathrm{MHz}$ bandwidth AOS.

All spectra were taken at the position of R.A. (1950) = $16^{\mathrm{h}} 29^{\mathrm{m}} 20.90$, decl. $(1950)=-24^{\circ} 22^{\prime} 13^{\prime \prime} .0$. Pointing was checked regularly on nearby planets and strong continuum sources and was found to be stable at the JCMT to better than $3^{\prime \prime}$. At the CSO, excursions up to $5^{\prime \prime}$ were found. For a number of molecules, small maps or five-point cross-observations were made to constrain the spatial extent of the emission. Examples of spectra obtained at the two telescopes are presented in $\S 4$.

\section{ANALYSIS}

As in Paper I, the data will be analyzed using both the rotation diagram method and more detailed statistical equilibrium calculations. In the rotation diagram method, the rotational temperature $T_{\mathrm{ROT}}$ and the total column density $N_{T}$ can be obtained through the relation

$$
\frac{3 k \int T_{\mathrm{MB}} d V}{8 \pi^{3} \mu^{2} v S}=\frac{N_{u}}{g_{u}}=\frac{N_{T}}{Q\left(T_{\mathrm{ROT}}\right)} e^{-E_{u} / k T_{\mathrm{ROT}}} .
$$

Here, $\mu, v$, and $S$ are the transition dipole moment, frequency,

\footnotetext{
${ }^{4}$ The Caltech Submillimeter Observatory is operated by the California Institute of Technology under funding from the US National Science Foundation (AST 93-13929).

5 The James Clerk Maxwell Telescope is operated by the Royal Observatory, Edinburgh, on behalf of the UK Particle Physics and Astronomy Research Council, the Netherlands Organization for Pure Research, and the National Research Council of Canada.
} 
and line strength, $E_{u}$ is the upper state energy, and $Q\left(T_{\mathrm{ROT}}\right)$ is the rotational partition function. The level degeneracies $g_{u}$, line strengths, and partition functions must be defined consistently. For these analyses we have used a substantially augmented version of the JPL line catalog and associated software available at the CSO (Poynter \& Pickett 1992; Groesbeck 1994) to construct the diagrams outlined below. The rotation diagram method assumes that the lines are optically thin and that the population distribution over the levels can be characterized by a single LTE temperature. In general, it provides a lower bound to the true kinetic temperature, but often overestimates the true column densities since all levels are assumed to be thermalized, regardless of their excitation. However, if the lines are optically thick, the rotational temperature is an overestimate of the kinetic temperature, and careful checks of the line opacities are an essential part of this procedure.

Because the assumption of LTE excitation is not necessarily valid for IRAS 16293-2422, we have also performed full statistical equilibrium calculations for those species for which collisional cross sections are available. Both collisional processes and radiative (de)excitation due to the $2.7 \mathrm{~K}$ background radiation field are taken into account, while the far-infrared radiation from IRAS $16293-2422$ is only important in the excitation of light hydrides such as HDO and possibly HNCO (Churchwell et al. 1986). The radiative transfer in the lines is performed using an escape probablity formulation. More details can be found in Jansen, van Dishoeck, \& Black (1994) and in Paper I.

Information about the spatial extent of the molecular emission can be obtained not only from mapping but also from observations of optically thick lines, especially if the source size of the molecules is equal to or smaller than the beam. This method assumes that the excitation temperature of the molecule has been determined independently, e.g., from optically thin isotopic lines. The observed main-beam antenna temperatures of the optically thick lines then provide a direct measure of the amount of beam dilution and thus of the effective source size. As will be shown below (see also Paper I), the various molecules are found to have very different source sizes, ranging from $\sim 3^{\prime \prime}$ to $20^{\prime \prime}$ or more.

\section{RESULTS}

\section{1. $\mathrm{HCO}^{+}, \mathrm{HCN}$, and $\mathrm{HNC}$}

The high-resolution $\mathrm{HCO}^{+}$and $\mathrm{HCN}$ 4-3 spectra obtained at the CSO are presented in Figure 1, and the HNC 4-3 line is included in Figure 2. Just like the ${ }^{12} \mathrm{CO}$ spectra presented in Paper I, the $\mathrm{HCO}^{+}$and $\mathrm{HCN}$ lines show broad, supersonic, wings as well as narrow self-absorption at $V_{\mathrm{LSR}}=4.2 \mathrm{~km} \mathrm{~s}^{-1}$ due to the cold surrounding molecular envelope. The fits to the line profiles are summarized in Table 1 . The fact that lines of both $\mathrm{HC}^{18} \mathrm{O}^{+}$and $\mathrm{HC}^{15} \mathrm{~N}$ are detected suggests that even the $\mathrm{H}^{13} \mathrm{CO}^{+}$and $\mathrm{H}^{13} \mathrm{CN}$ lines (included in Figs. 13 and 15) are still somewhat optically thick. Because the $\mathrm{H}^{13} \mathrm{CN} 4-3$ line is also blended with an $\mathrm{SO}_{2}$ line, no reliable rotational temperatures can be derived for this species.

The results of statistical equilibrium calculations for $\mathrm{HCO}^{+}$ and $\mathrm{HCN}$ are summarized in Figure 3, where the variation in the 4-3/3-2 line ratio with density and temperature is presented for optically thin lines. It is seen that for both species, the line ratio is primarily sensitive to density. The upper limit on the $\mathrm{HC}^{15} \mathrm{~N} 4-3 / 3-2$ ratio indicates that $n\left(\mathrm{H}_{2}\right)<1 \times 10^{7}$ $\mathrm{cm}^{-3}$, consistent with densities inferred from the Si- and S-

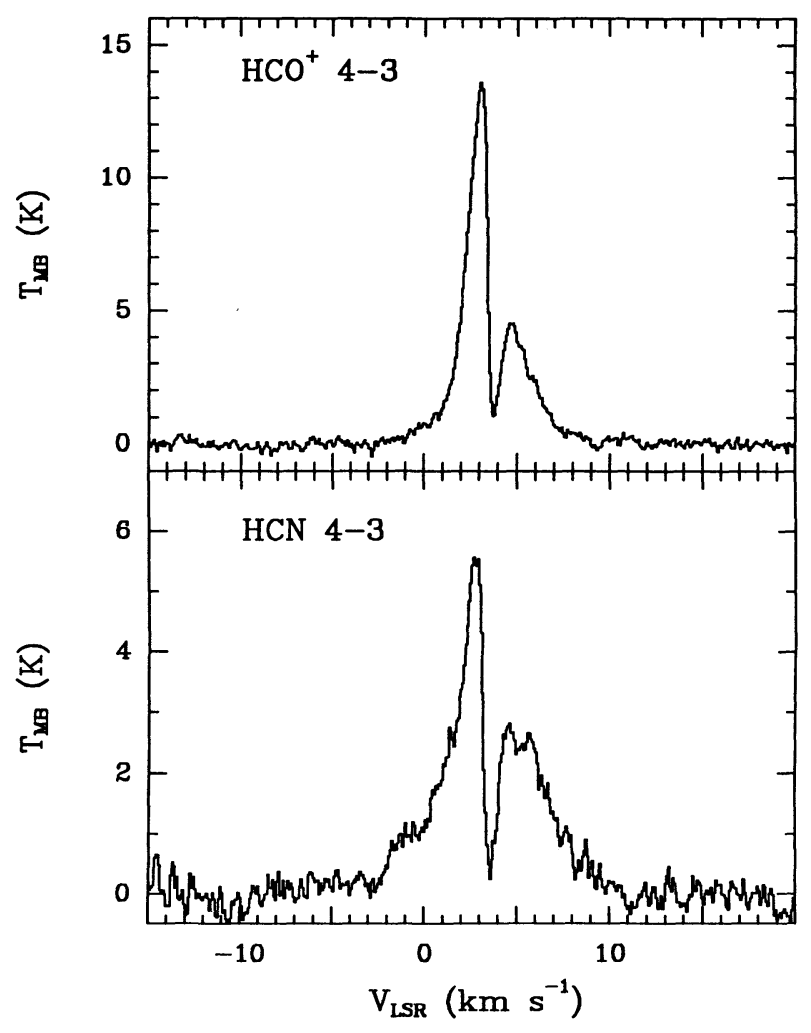

Fig. 1.-Top panel, High-resolution CSO spectrum of the $\mathrm{HCO}^{+}$ $J=4 \rightarrow 3$ line toward IRAS $16293-2422$. Lower panel, CSO spectrum of the HCN $J=4 \rightarrow 3$ line.

bearing species (Paper I). The same limit is found from the $\mathrm{H}^{13} \mathrm{CO}^{+}{ }^{4-3 / 3-2}$ lines for $T_{\text {kin }}>100 \mathrm{~K}$; for lower temperatures no constraints on the density are obtained, except that it must be of order $10^{7} \mathrm{~cm}^{-3}$ or greater.

If the excitation temperature of $\mathrm{HCO}^{+}$is assumed to be close to that of the dust temperature of $\sim 40 \mathrm{~K}$ (Walker et al. 1986; Mezger et al. 1992), then the observed main-beam temperature of the optically thick 4-3 line of $\sim 20 \mathrm{~K}$ (corrected for self-absorption) in a $20^{\prime \prime}$ beam suggests an area filling factor of $\sim 0.5$ or a source size of $\sim 26^{\prime \prime}$. For an excitation temperature of $\sim 80 \mathrm{~K}$, comparable to that found for $\mathrm{SO}_{2}$ and $\mathrm{CH}_{3} \mathrm{OH}$ (see below), the source size becomes $\sim 13^{\prime \prime}$. Similarly, the HCN peak temperature of $\sim 6.5 \mathrm{~K}$ suggests source sizes of $\sim 10^{\prime \prime}$ and $\sim 6^{\prime \prime}$, respectively.

In contrast with HCN, the HNC 4-3 line does not show any self-absorption. Also, the line is considerably narrower than that of $\mathrm{HCN}$. $\mathrm{HN}^{13} \mathrm{C} 3-2$ is only marginally detected, indicating that the main isotopic lines are not highly optically thick. Because of the limited number of observed lines, no excitation analysis has been performed for this molecule.

\section{2. $\mathrm{H}_{2} \mathrm{CO}$}

Many lines of $\mathrm{H}_{2} \mathrm{CO}$ have been detected toward IRAS 16293-2422, which are summarized in Table 2 (see also Mangum \& Wootten 1993). Examples of spectra are given in Figures 2, 4, and 5 . It is seen that the strongest, lower lying lines of $\mathrm{H}_{2} \mathrm{CO}$ are again self-absorbed, but that the higher lines show only emission. The lines appear somewhat narrower than those of $\mathrm{HCN}$, and the limits on $\mathrm{H}_{2}{ }^{13} \mathrm{CO}$ suggest that most lines are optically thin. 


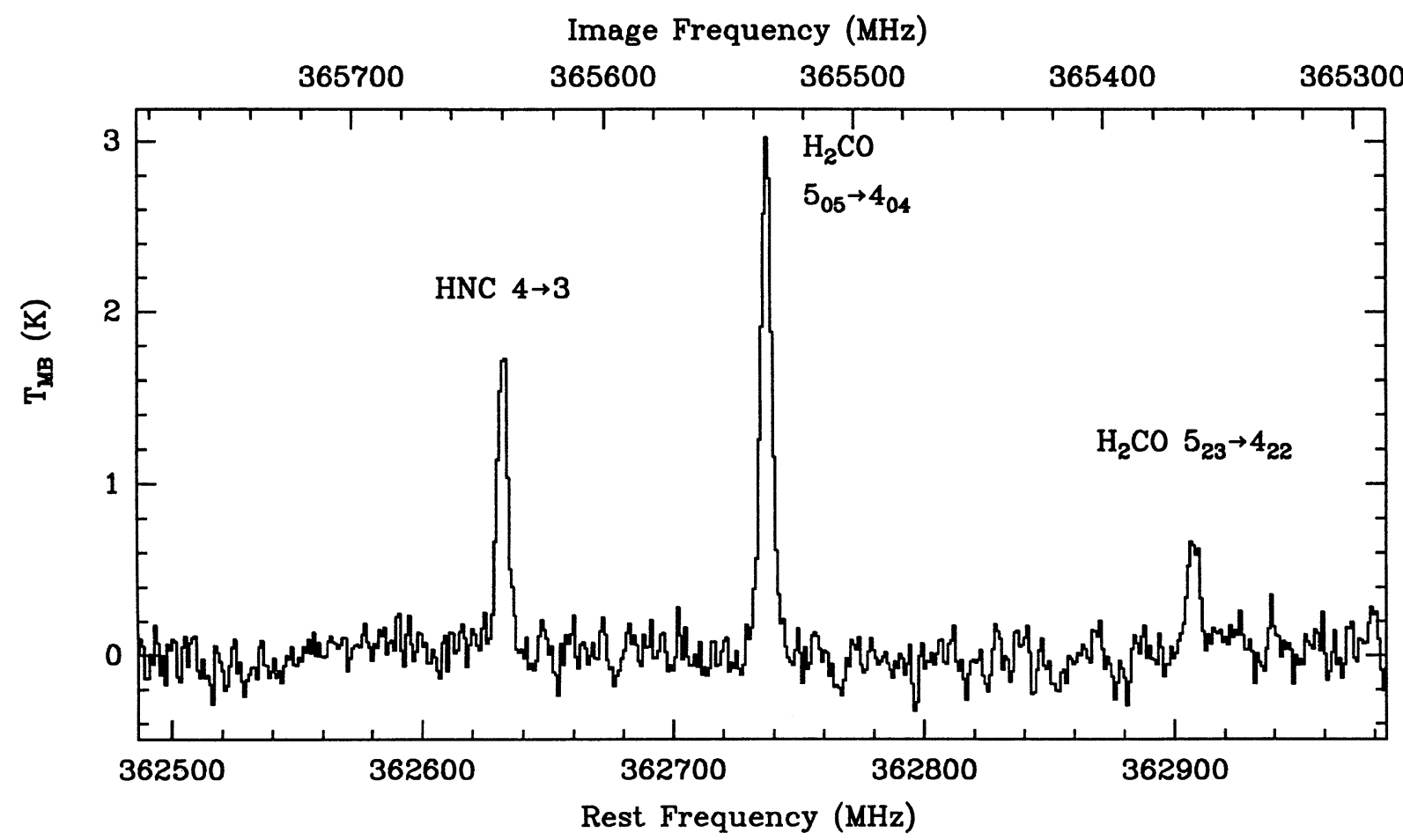

FIG. 2. $-\mathrm{CSO}$ spectrum containing highly excited lines of para- $\mathrm{H}_{2} \mathrm{CO}$ and $\mathrm{HNC}$

In Figure 6, the rotation diagram for $\mathrm{H}_{2} \mathrm{CO}$ is presented. The various lines can be described fairly well by a single rotational temperature of $T_{\mathrm{ROT}} \approx 80 \pm 10 \mathrm{~K}$ and a column density of $N\left(\mathrm{H}_{2} \mathrm{CO}\right)=(2.1 \pm 0.3) \times 10^{14} \mathrm{~cm}^{-2}$. The point deviating most strongly from this fit is due to the $5_{15}-4_{14}$ line, which may be caused by optical depth effects. The $\mathrm{H}_{2}{ }^{13} \mathrm{CO} 5_{15}-4_{14}$ line is unfortunately blended with $\mathrm{H}_{2} \mathrm{CS}$. If the main isotopic line is highly optically thick, the derived source size is close to $\sim 5^{\prime \prime}$. More likely, the line is only moderately saturated and the $\mathrm{H}_{2} \mathrm{CO}$ source size larger than $5^{\prime \prime}$.

The $\mathrm{H}_{2} \mathrm{CO}$ molecule is a very powerful diagnostic of the local kinetic temperature and density (e.g., van Dishoeck, Jansen, \& Phillips 1993b; Mangum \& Wootten 1993). The sensitivity of various line ratios to these physical parameters is presented in Figure 7. From the ratios of lines within the same $K_{p}$ ladder (e.g., $5_{15}-4_{14} / 3_{13}-2_{12}$ and $5_{05}-4_{04} / 3_{03}-2_{02}$ ), the density is found to be $n\left(\mathrm{H}_{2}\right) \approx(1-4) \times 10^{6} \mathrm{~cm}^{-3}$, somewhat lower than that derived in Paper I from, e.g., $\mathrm{H}_{2} \mathrm{CS}$. This may again be partly due to an underestimate of the optical depth in the $5_{15}-4_{14}$ line (see also below). The kinetic temperature is best determined from lines originating from different $K_{p}$ ladders, especially those of para- $\mathrm{H}_{2} \mathrm{CO}$. The $3_{22}-2_{21} / 3_{03}-2_{02}$

TABLE 1

OBSERVATIONS OF $\mathrm{HCO}^{+}, \mathrm{HCN}, \mathrm{HNC}, \mathrm{HC}_{3} \mathrm{~N}$, AND ISOTOPES

\begin{tabular}{|c|c|c|c|c|c|c|}
\hline Molecule & Line & $\begin{array}{l}\text { Frequency } \\
(\mathrm{MHz})\end{array}$ & $\int_{\left(\mathrm{K} \mathrm{km} \mathrm{s}^{-1}\right)} T_{\mathrm{MB}} d V$ & $\begin{array}{l}T_{\mathrm{MB}} \\
(\mathbf{K})\end{array}$ & $\begin{array}{c}\Delta V \\
\left(\mathrm{~km} \mathrm{~s}^{-1}\right)\end{array}$ & Telescope \\
\hline $\mathrm{HCO}^{+}$ & 4-3. & 356734.3 & 68.0 & 20.5 & 3.11 & $\mathrm{CSO}^{\mathrm{a}}$ \\
\hline \multirow[t]{2}{*}{$\mathrm{H}^{13} \mathrm{CO}^{+}$} & $3-2 \ldots \ldots \ldots$ & 260255.5 & 3.84 & 1.31 & 2.74 & JCMT \\
\hline & $4-3 \ldots \ldots \ldots$ & 346998.5 & 6.05 & 1.98 & 2.86 & CSO \\
\hline $\mathrm{HC}^{18} \mathrm{O}^{+}$ & $4-3 \ldots \ldots \ldots$ & 340633.0 & 1.73 & 0.40 & 4.09 & CSO \\
\hline $\mathrm{HCN}$ & $4-3$. & 354505.5 & 35.0 & 6.49 & 5.07 & $\mathrm{CSO}^{\mathrm{a}}$ \\
\hline \multirow[t]{2}{*}{$\mathrm{H}^{13} \mathrm{CN}$} & $3-2$. & 259011.7 & 3.45 & 0.56 & 5.85 & JCMT \\
\hline & $4-3$. & 345339.8 & 8.13 & 1.22 & 6.28 & $\mathrm{CSO}^{\mathrm{b}}$ \\
\hline \multirow[t]{2}{*}{$\mathrm{HC}^{15} \mathrm{~N}$} & 3-2 ........ & 258157.3 & 1.82 & 0.27 & 6.16 & JCMT \\
\hline & $4-3 \ldots \ldots \ldots$ & 344200.3 & & $<0.33$ & & CSO \\
\hline HNC & $4-3 \ldots \ldots$ & 362629.9 & 7.65 & 1.72 & 4.18 & CSO \\
\hline $\mathrm{HN}^{13} \mathrm{C}$ & $3-2$. & 261263.4 & 1.33 & 0.15 & 8.0: & $\mathrm{JCMT}^{\mathrm{c}}$ \\
\hline \multirow[t]{3}{*}{$\mathrm{HC}_{3} \mathrm{~N}$} & $24-33 \ldots \ldots$ & 218324.8 & 0.51 & 0.12 & 3.83: & $\mathrm{JCMT}^{\mathrm{c}}$ \\
\hline & $27-26 \ldots \ldots$ & 245606.4 & 0.91 & 0.11 & 7.67 & JCMT \\
\hline & $28-27 \ldots \ldots$ & 254699.6 & 0.91 & 0.12 & 6.99 & JCMT \\
\hline
\end{tabular}

a Self-absorbed; fit parameters refer to emission only.

${ }^{b}$ Blend with $\mathrm{SO}_{2}$.

${ }^{\mathrm{c}}$ Colon indicates uncertain value. 


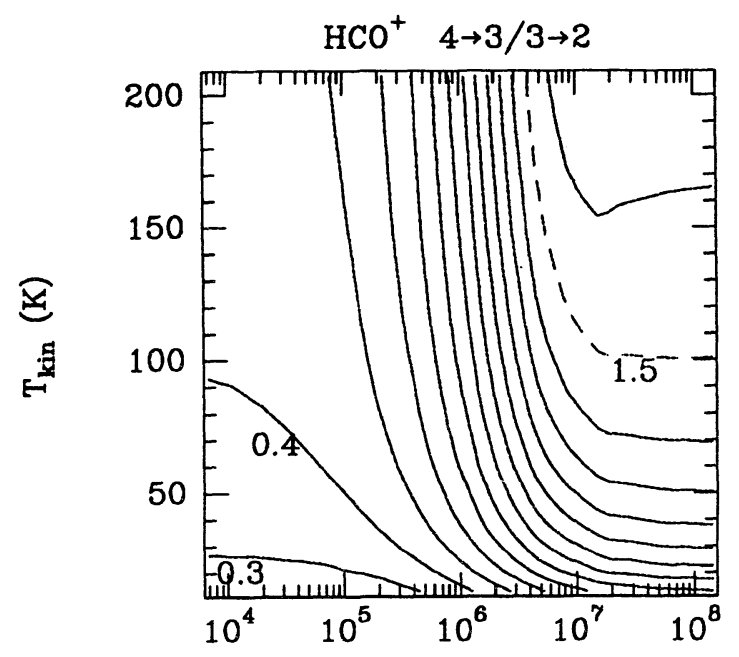

HCN $\quad 4 \rightarrow 3 / 3 \rightarrow 2$
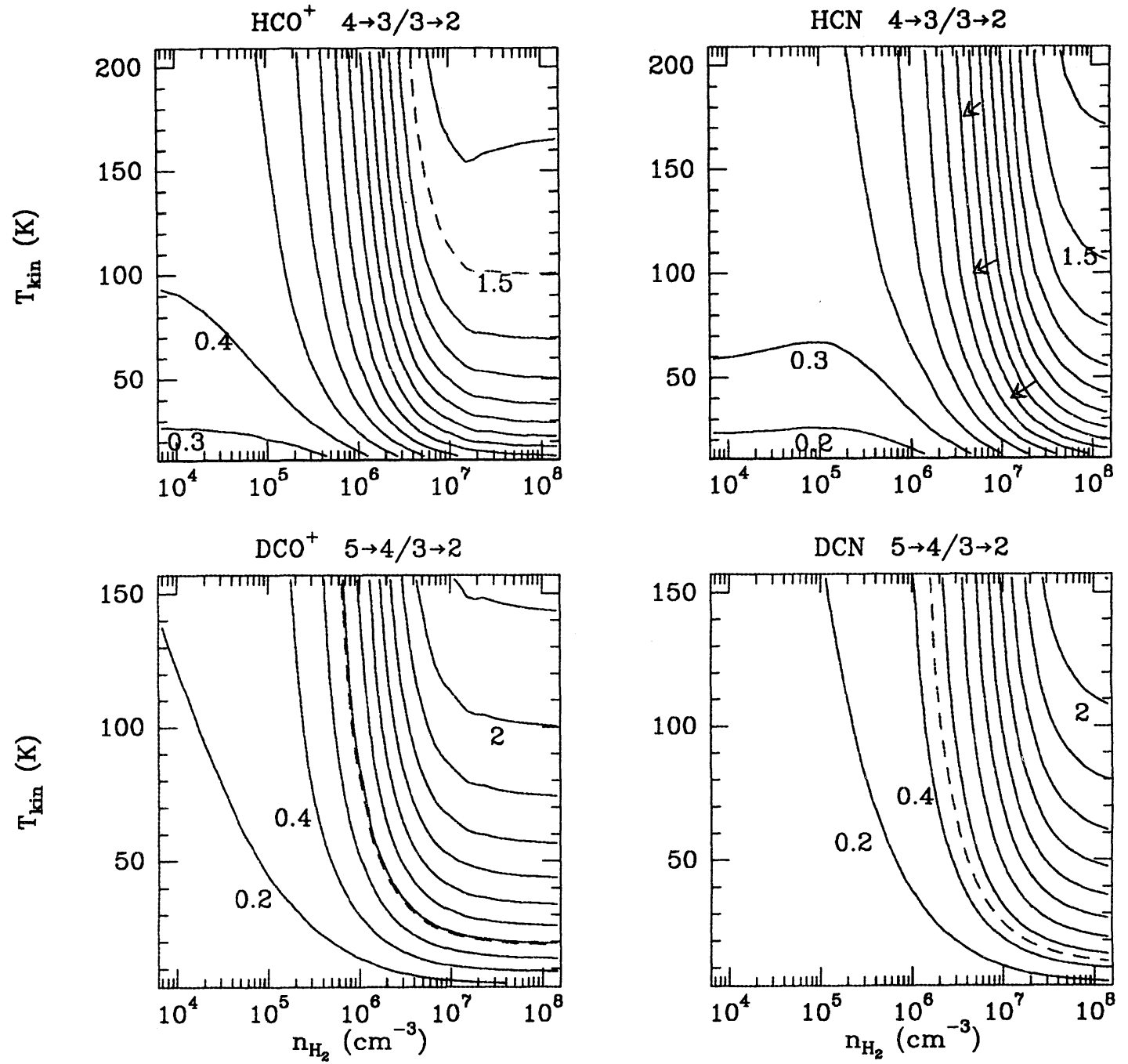

FIG. 3.-Variation of line antenna temperature ratios with kinetic temperature and density obtained from the statistical equilibrium calculations for $\mathrm{H}^{13} \mathrm{CO}^{+}$, $\mathrm{HC}^{15} \mathrm{~N}, \mathrm{DCO}^{+}$, and DCN. The solid lines are the model results, and the dashed lines indicate the observed ratios. The contour values are indicated in the plots. The adopted column density for $\mathrm{H}^{13} \mathrm{CO}^{+}$is $N=2 \times 10^{12} \mathrm{~cm}^{-2}$ with a line width $\Delta V=2.8 \mathrm{~km} \mathrm{~s}^{-1}$; for $\mathrm{HC}^{15} \mathrm{~N}, N=1.5 \times 10^{12} \mathrm{~cm}^{-2}$ with $\Delta V=6 \mathrm{~km} \mathrm{~s}^{-1}$; for DCO ${ }^{+}$, $N=5 \times 10^{12} \mathrm{~cm}^{-2}$ with $\Delta V=2 \mathrm{~km} \mathrm{~s}^{-1}$; for DCN, $N=5 \times 10^{12} \mathrm{~cm}^{-2}$ with $\Delta V=4 \mathrm{~km} \mathrm{~s}^{-1}$.

TABLE 2

OBSERVATIONS OF $\mathrm{H}_{2} \mathrm{CO}$

\begin{tabular}{|c|c|c|c|c|c|}
\hline $\begin{array}{l}\text { Molecule } \\
\text { and Line }\end{array}$ & $\begin{array}{c}\text { Frequency } \\
(\mathrm{MHz})\end{array}$ & $\underset{\left(\mathrm{K} \mathrm{km} \mathrm{s}^{-1}\right)}{\int} T_{\mathrm{MB}} d V$ & $\begin{array}{l}T_{\mathrm{MB}} \\
(\mathbf{K})\end{array}$ & $\underset{\left(\mathrm{km} \mathrm{s}^{-1}\right)}{\Delta V}$ & Telescope \\
\hline \multicolumn{6}{|l|}{$\mathrm{H}_{2} \mathrm{CO}:$} \\
\hline $3_{13}-2_{12} \ldots \ldots \ldots \ldots$ & 211211.5 & 23.1 & 6.75 & 3.21 & $\mathrm{JCMT}^{\mathrm{a}}$ \\
\hline $9_{18}-9_{19} \ldots \ldots \ldots \ldots$ & 216568.6 & 0.40 & 0.13 & 2.84 & JCM \\
\hline $3_{03}-2_{02} \ldots \ldots \ldots \ldots$ & 218222.2 & 13.2 & 3.76 & 3.31 & $\mathrm{JCMT}^{\mathrm{a}}$ \\
\hline $3_{22}-22_{21} \ldots \ldots \ldots \ldots \ldots$ & 218475.6 & 3.35 & 0.82 & 3.89 & JCMT \\
\hline $3_{12}-2, \ldots \ldots \ldots \ldots$ & 225697.8 & 20.0 & 6.09 & 3.08 & $\mathrm{JMCT}^{\mathrm{a}}$ \\
\hline $5_{15}-4_{14} \ldots \ldots \ldots \ldots$ & 351768.7 & 19.2 & 4.23 & 4.26 & CSO \\
\hline $5_{05}-4_{04} \ldots \ldots \ldots \ldots$ & 362735.9 & 13.5 & 2.80 & 4.52 & CSO \\
\hline $5_{24}-4_{23} \ldots \ldots \ldots \ldots$ & 363945.9 & 8.27 & 1.45 & 5.34 & CSO \\
\hline $5_{42 / 41}-4_{41 / 40} \cdots \cdots$ & 364102.8 & 2.10 & 0.33 & 5.99 & CSO \\
\hline 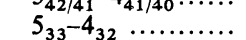 & 364275.2 & 6.93 & 1.43 & 4.55 & CSO \\
\hline $5_{32}-4_{31} \ldots \ldots \ldots \ldots$ & 364289.0 & 8.27 & 1.50 & 5.18 & CSO \\
\hline $5_{23}-4_{22} \ldots \ldots \ldots \ldots$ & 365363.4 & 3.65 & 0.78 & 4.42 & CSO \\
\hline \multicolumn{6}{|l|}{$\mathrm{H}_{2}{ }^{13} \mathrm{CO}$} \\
\hline $3_{22}-2_{21} \ldots \ldots \ldots \ldots$ & 213037.4 & $\ldots$ & $\leq 0.18$ & $\ldots$ & JCMT \\
\hline $3_{21}-2_{20} \ldots \ldots \ldots \ldots$ & 213293.6 & $\ldots$ & $\leq 0.09$ & $\ldots$ & JCMT \\
\hline $3_{12}-2_{11} \ldots \ldots \ldots \ldots$ & 219908.5 & $\ldots$ & $\leq 0.29$ & $\ldots$ & JCMT \\
\hline $5_{05}-4$ & 353811.9 & $\ldots$ & $\leq 0.13$ & & CSO \\
\hline $5_{15}-4_{14} \cdots \cdots \cdots \cdots$ & 343325.7 & 1.82 & 0.33 & 5.07 & $\mathrm{CSO}^{\mathrm{b}}$ \\
\hline
\end{tabular}

a Self-absorbed; the fit parameters correspond to the emission part only.

b Blend with $\mathrm{H}_{2} \mathrm{CS}$. 


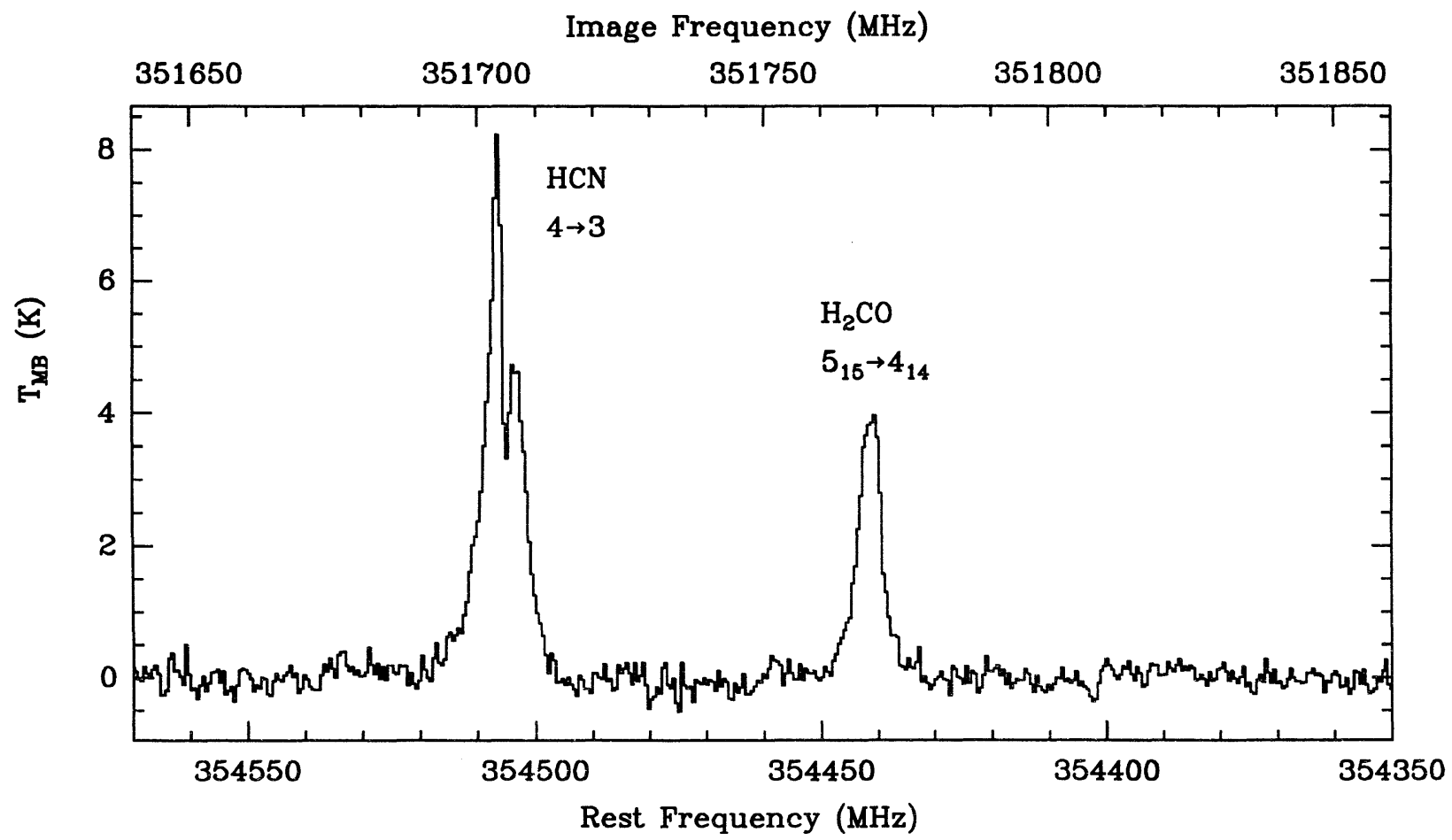

FIG. 4.- CSO spectrum containing highly excited lines of $\mathrm{HCN}$ and ortho- $\mathrm{H}_{2} \mathrm{CO}$

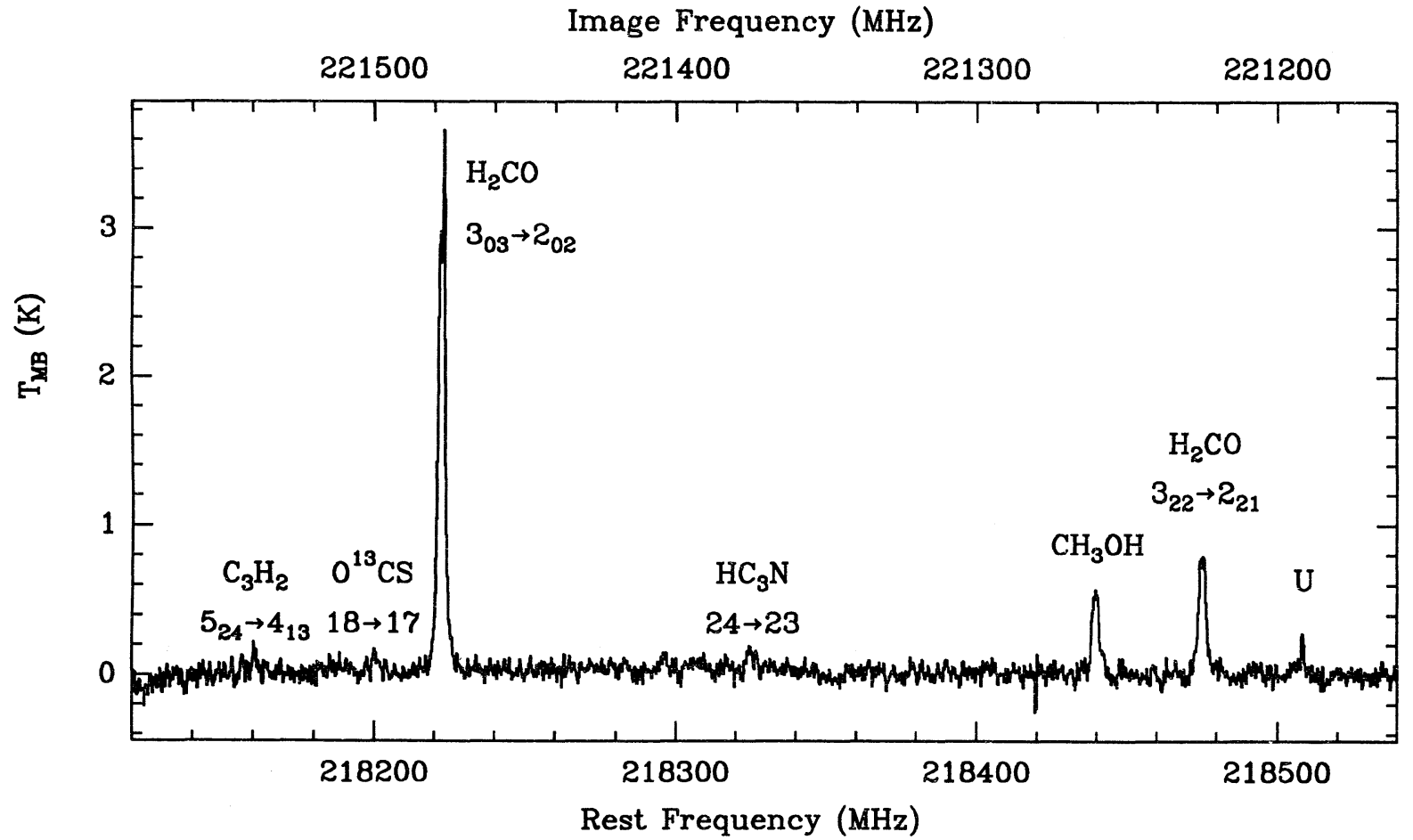

FIG. 5.-JCMT spectrum near $218.4 \mathrm{GHz}(\mathrm{LSB})$, which contains the para- $\mathrm{H}_{2} \mathrm{CO} J_{K_{p}}=3_{K_{p}} \rightarrow 2_{K_{p}}$ lines. Also visible are lines of $\mathrm{C}_{3} \mathrm{H}_{2}, \mathrm{O}^{13} \mathrm{CS}, \mathrm{HC}_{3} \mathrm{~N}, \mathrm{CH}_{3} \mathrm{OH}$, and an unidentified line. 

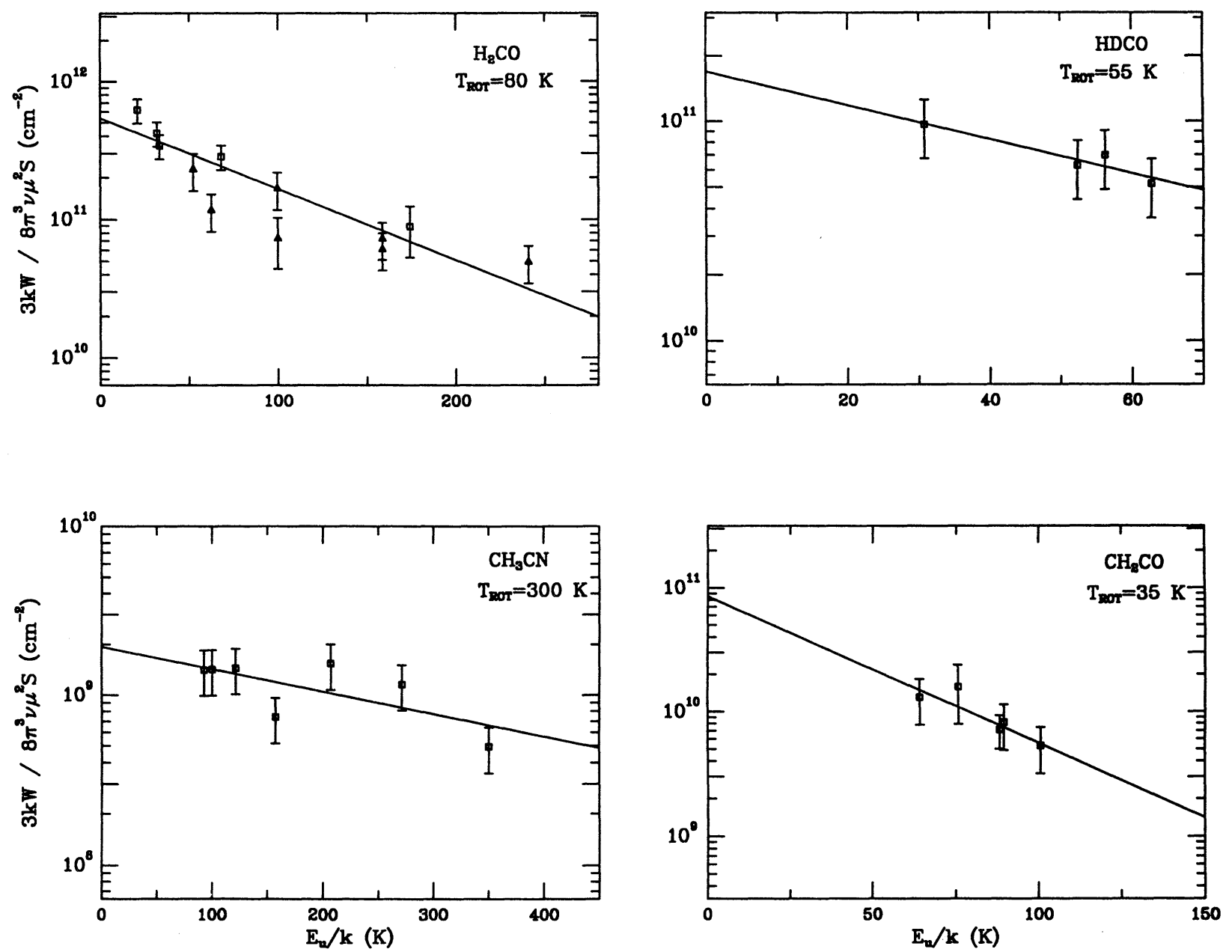

FIG. 6.-Rotation diagram plots of the $\mathrm{CSO} / \mathrm{JCMT}$ data for $\mathrm{H}_{2} \mathrm{CO}, \mathrm{HDCO}, \mathrm{CH}_{3} \mathrm{CN}$, and $\mathrm{CH}_{2} \mathrm{CO}$. The JCMT data points are presented as squares, while the CSO data are labeled with triangles. The error bars are $20 \%$ of the line intensities, or $30 \%$ in the case of the weakest lines. Upper limits are denoted by arrows.

line ratio suggests a temperature $T_{\mathrm{kin}} \approx 60 \pm 15 \mathrm{~K}$, whereas the $5_{24}-4_{23} / 5_{05}-4_{04}$ and $5_{42}-4_{41} / 5_{24}-4_{23}$ ratios indicate somewhat higher temperatures of $T_{\text {kin }} \approx 80 \pm 20 \mathrm{~K}$ and $T_{\text {kin }} \approx 140$ $\pm 25 \mathrm{~K}$, respectively. Mangum \& Wootten (1993) derived a similarly high temperature, $T_{\text {kin }} \approx 150_{-20}^{+85} \mathrm{~K}$, from the para$\mathrm{H}_{2} \mathrm{CO} 5-4$ lines. Their inferred density $n\left(\mathrm{H}_{2}\right) \approx(4 \pm 3) \times 10^{5}$ $\mathrm{cm}^{-3}$ is somewhat lower and less well constrained than in our case, because they lacked 3-2 data for this source.

The temperature and density derived from ratios involving lower lying lines such as $3_{13}-2_{12}, 3_{12}-2_{11}$, and $3_{03}-2_{02}$ may be systematically lower than those found from other lines or species because part of the emission in these lines originates from the colder, less dense part of the envelope. In Figure 8, a CSO map over a $2^{\prime} \times 2^{\prime}$ area is presented for the $3_{03}-2_{02}$ line. It is seen that the peak emission centered on the young stellar objects is unresolved in the $32^{\prime \prime}$ CSO beam, but that extended emission at the level of $\sim 30 \%$ of the peak intensity is found. If this extended contribution is subtracted from the central emission, then the $3_{22}-2_{21} / 3_{03}-2_{02}$ ratio gives $T_{\text {kin }} \approx 100_{-20}^{+40} \mathrm{~K}$, consistent with the values derived from the higher lying lines. Here it is assumed that the extended cold component does not emit significantly in the $3_{22}-2_{21}$ line. The densities obtained from ratios involving the lower lying lines increase to $n\left(\mathrm{H}_{2}\right) \approx$
$10^{7} \mathrm{~cm}^{-3}$, if the contribution of the extended emission is assumed to be similar for the $3_{13}-2_{12}$ line.

The map presented in Figure 8 also reveals strong $\mathrm{H}_{2} \mathrm{CO}$ emission $\sim 60^{\prime \prime}$ east of IRAS $16293-2422$, in the general direction of the outflow(s) (Mizuno et al. 1990). This enhanced $\mathrm{H}_{2} \mathrm{CO}$ emission appears to lie just outside the cold clump of $\mathrm{DCO}^{+}$and $\mathrm{NH}_{3}$ emission found by Wootten \& Loren (1987) $\sim 100^{\prime \prime}$ east of the IRAS source.

\section{3. $\mathrm{CH}_{3} \mathrm{OH}$}

The largest number of lines observed from a single molecule originate from methanol. Table 3 lists the $53 \mathrm{CH}_{3} \mathrm{OH}$ lines detected toward IRAS $16293-2422$. Spectra of the $5_{K}-4_{K}$ band at $241 \mathrm{GHz}$ and the $7_{K}-6_{K}$ band at $338 \mathrm{GHz}$ are shown in Figures 9 and 10. The rotation diagram for this molecule is presented in Figure 11, and it is seen that the lines are fairly well fit by a single temperature of $T_{\mathrm{ROT}} \approx 85 \pm 6 \mathrm{~K}$ with $N\left(\mathrm{CH}_{3} \mathrm{OH}\right) \approx(8.8 \pm 1.0) \times 10^{14} \mathrm{~cm}^{-2}$. No systematic offset between the CSO and JCMT data is found. The scatter in the data around the best-fitting line is most likely caused by non-LTE excitation effects, as has also been found for $\mathrm{CH}_{3} \mathrm{OH}$ toward Sgr B2 (Sutton et al. 1991) and W3( $\left.\mathrm{H}_{2} \mathrm{O}\right)$ (Helmich et al. 1994). 

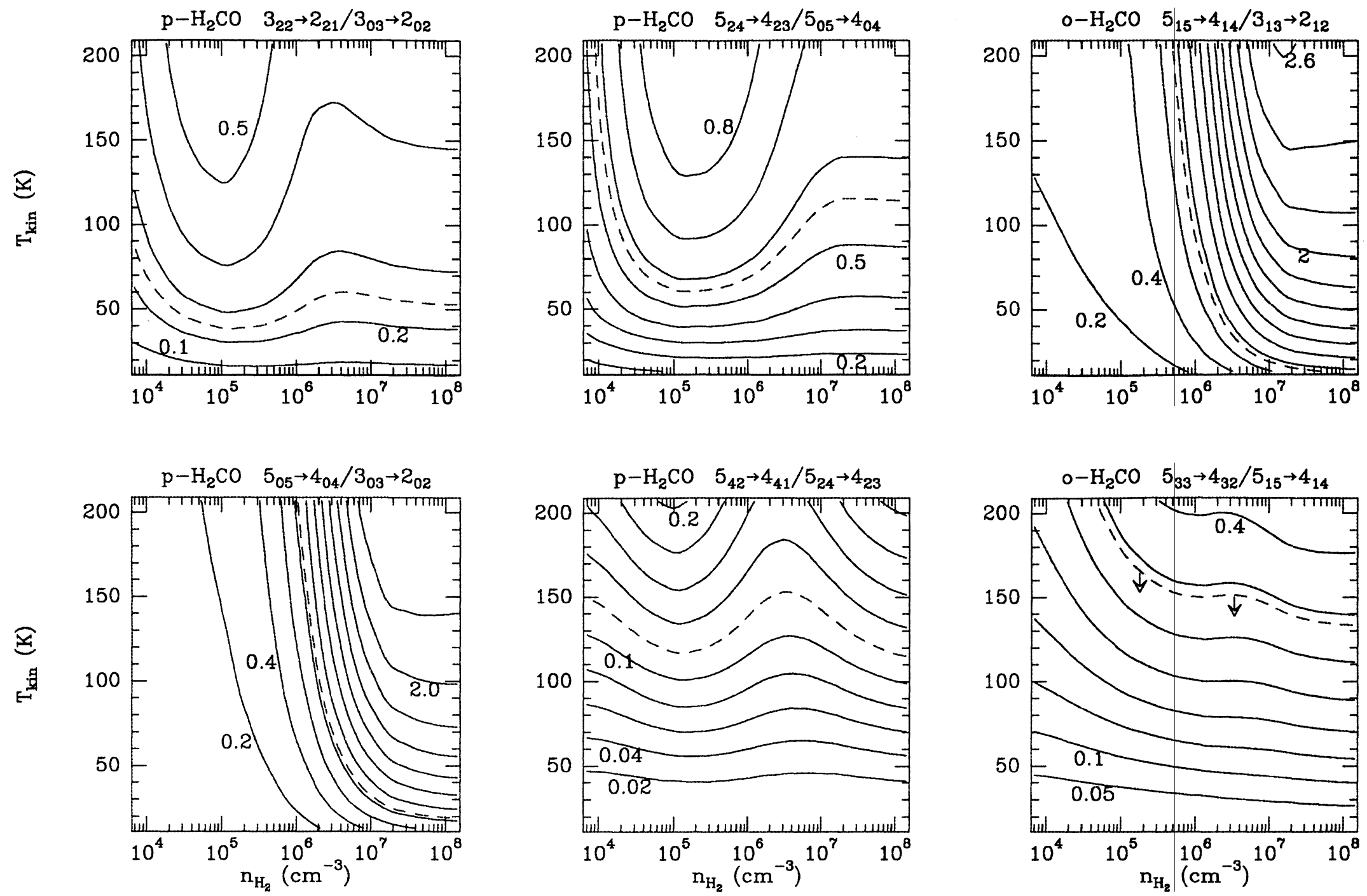

FIG. 7.-Variation of line antenna temperature ratios with kinetic temperature and density obtained from the statistical equilibrium calculations for para- and ortho- $\mathrm{H}_{2} \mathrm{CO}$. The full lines are the model results, and the dashed lines indicate the observed ratios. The contour values are indicated in the plots. The adopted column density for para- $\mathrm{H}_{2} \mathrm{CO}$ is $N=4.5 \times 10^{13} \mathrm{~cm}^{-2}$ with a line width $\Delta V=3.3 \mathrm{~km} \mathrm{~s}^{-1}$. For ortho- $\mathrm{H}_{2} \mathrm{CO}$, the adopted $N=1.5 \times 10^{14} \mathrm{~cm}^{-2}$ with $\Delta V=3.2 \mathrm{~km} \mathrm{~s}^{-1}$. The variation of the $5_{15^{-4}} 4_{14} / 3_{12}-2_{11}$ ratio with temperature and density is similar to that of the $5,-414 / 3_{13}-2_{12}$ ratio. 


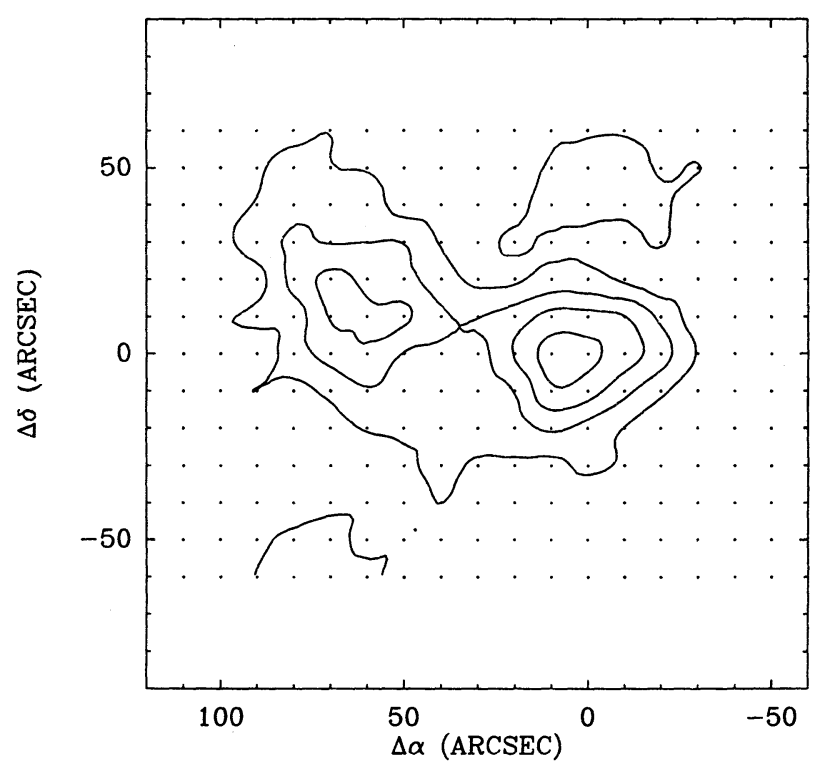

FIG. 8.-Map of the integrated $\mathrm{H}_{2} \mathrm{CO}_{33}-2_{02}$ line intensity obtained with the CSO in a 32" beam. The $(0,0)$ refers to the IRAS $16293-2422$ position used in this paper. The contours range from $30 \%$ to $90 \%$ of the peak integrated antenna temperature of $13.2 \mathrm{~K} \mathrm{~km} \mathrm{~s}^{-1}$ in steps of $20 \%$.

The limit on the strongest ${ }^{13} \mathrm{CH}_{3} \mathrm{OH} 5_{K}-4{ }_{K}$ lines indicates that the optical depth in the main isotopic lines cannot be larger than $\tau \leq 6$. If the strongest $5_{0}-4_{0} A^{+}$line were indeed this optically thick, the observed main-beam temperature combined with the excitation temperature of $\sim 85 \mathrm{~K}$ would imply a source size of $\sim 1^{\prime \prime}$. More likely, the $\mathrm{CH}_{3} \mathrm{OH}$ lines are optically thin, or at most moderately optically thick, and originate from a larger region. The $7_{K}-6_{K}$ band has also been observed with the JCMT, and the resulting main-beam temperatures are systematically higher than those found at the CSO. The ratio of the $7{ }_{0}-6_{0} A^{+}$main-beam temperature in the JCMT $15^{\prime \prime}$ and CSO $20^{\prime \prime}$ beams is $\sim 1.5 \pm 0.2$, suggesting a source size of $\sim 10^{\prime \prime}$.

The $\mathrm{CH}_{3} \mathrm{OH} 7_{K}-6_{K}$ band at $338 \mathrm{GHz}$ has been mapped with the JCMT $15^{\prime \prime}$ beam at half-beam spacings. The resulting maps in the various lines are presented in Figure 12. The apparent extent of the emission in the $7_{0}-6_{0} A^{+}$line is $15^{\prime \prime} \times 18^{\prime \prime}$, which corresponds to a source size of $\sim 11^{\prime \prime}$ assuming a $15^{\prime \prime}$ Gaussian beam shape, consistent with the above. Since the apparent size is comparable to the beam size, the uncertainty in this determination is large, and the source size could well be as small as a few arcseconds. No significant difference in source size is found between lower and higher excitation lines. Altogether, the $\mathrm{CH}_{3} \mathrm{OH}$ emission appears to originate from a source $\sim 10^{\prime \prime} \pm 5^{\prime \prime}$.

\section{4. $\mathrm{CH}_{3} \mathrm{CN}, \mathrm{HC}_{3} \mathrm{~N}, \mathrm{CH}_{3} \mathrm{C}_{2} \mathrm{H}, \mathrm{HNCO}$, and $\mathrm{CH}_{2} \mathrm{CO}$}

Although the lines of $\mathrm{CH}_{3} \mathrm{CN}$ are weak compared to those of $\mathrm{CH}_{3} \mathrm{OH}$, the molecule is definitely present in IRAS $16293-2422$. The clearest detection is provided by the $14_{K}-13_{K}$ band shown in Figure 13. The lines are broad (see Table 4), and their relative strengths are consistent with a high excitation temperature, $T_{\mathrm{ROT}} \approx 300_{-150}^{+200} \mathrm{~K}$. The total column density for this temperature is $N\left(\mathrm{CH}_{3} \mathrm{CN}\right)=(3 \pm 2) \times 10^{13}$ $\mathrm{cm}^{-2}$, but it is stressed that the high excitation temperature could be caused by high optical depth in the lines. If the excitation temperature of $\mathrm{CH}_{3} \mathrm{CN}$ were comparable to that of $\mathrm{CH}_{3} \mathrm{OH}$, the implied source size would be less than $<1^{\prime \prime}$. In either case, the extent of $\mathrm{CH}_{3} \mathrm{CN}$ is small.

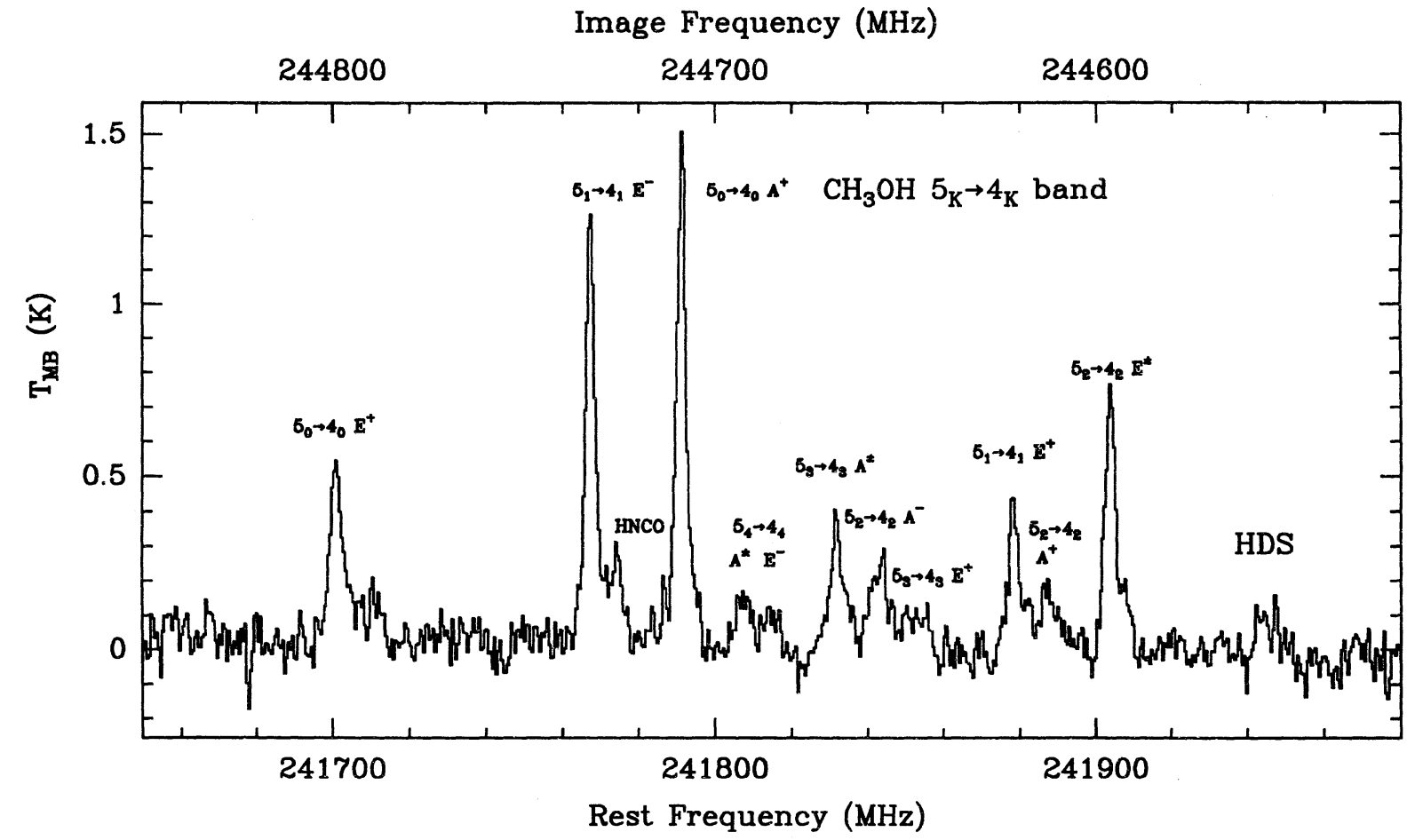

FIG. 9.-JCMT spectrum near $241.8 \mathrm{GHz}(\mathrm{LSB})$, which contains the $\mathrm{CH}_{3} \mathrm{OH} 5_{K}-4_{K}$ band. Also visible are lines of HDS and $\mathrm{HNCO}$. 
TABLE 3

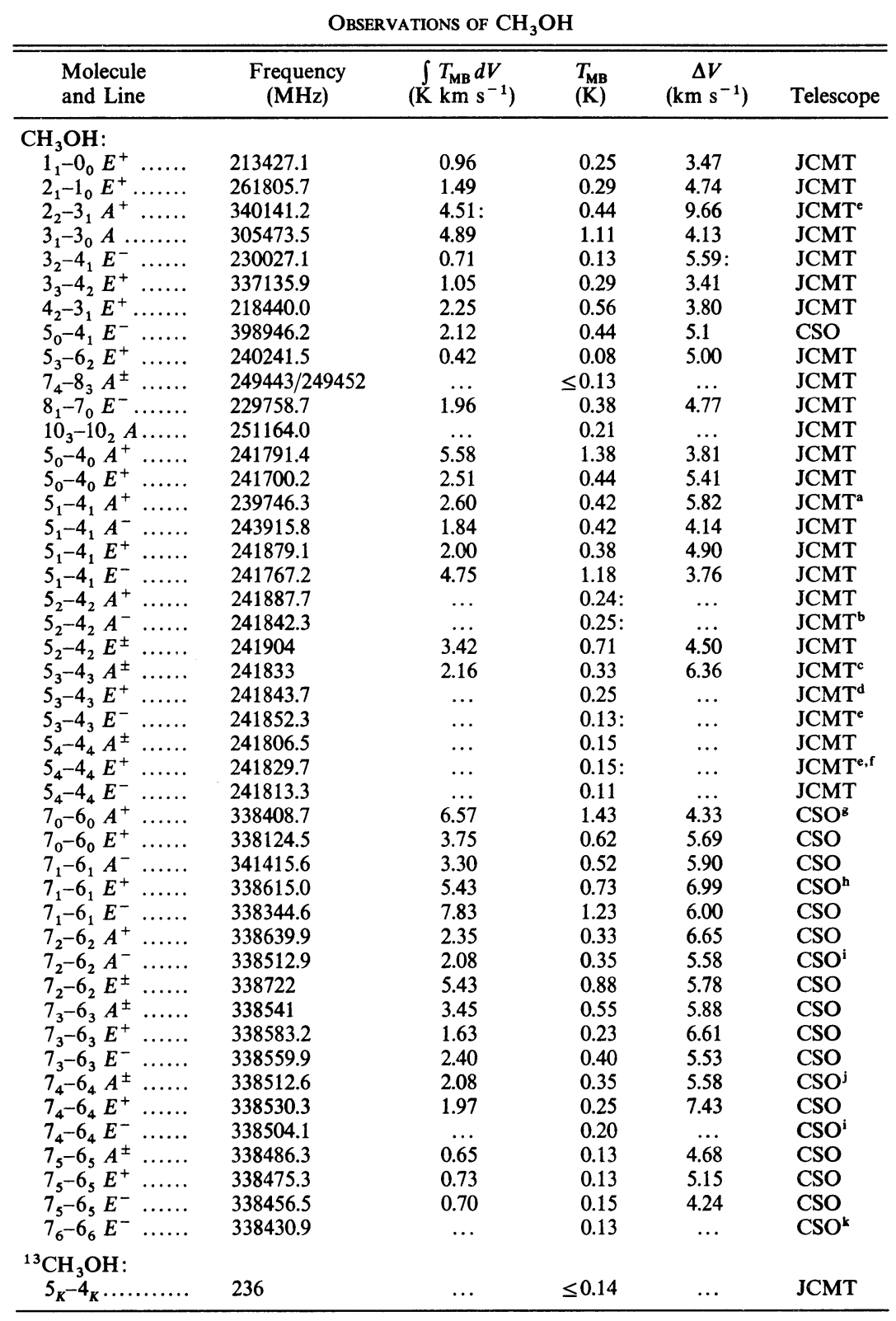

a At edge of spectrum.

b Blend with $5_{3}-4_{3} E^{+}$.

c Blend with $5_{4}-4_{4} E^{+}$.

d Blend with $5_{2}-4_{2} A^{-}$.

e Colon indicates uncertain value.

f Blend with $5_{3}-4_{3} A^{ \pm}$.

g Blend with $7_{6}-6_{6} E^{-}$

h Blend with $\mathrm{SO}_{2} 20_{4,19}-19_{2,18}$.

i Blend with $74-64 A^{ \pm}$

j Blend with $72-6_{2} A^{-}$.

k Blend with $7_{0}-6_{0} A^{+}$

Three lines due to $\mathrm{HC}_{3} \mathrm{~N}$ have been detected (see Fig. 5). Because $\mathrm{HC}_{3} \mathrm{~N}$ is a heavy linear rotor, the submillimeter lines all originate from high-lying levels at energies greater than 100 $\mathrm{K}$. The corresponding rotational temperature is $\sim 115 \mathrm{~K}$, with substantial uncertainty. $\mathrm{HC}_{3} \mathrm{~N}$ has a large dipole moment, $\mu \approx 3.6 \mathrm{D}$, so that not only high temperatures but also high densities are needed to populate these levels. Statistical equi- librium calculations indicate that $T_{\mathrm{kin}} \gtrsim 80 \mathrm{~K}$ and $n\left(\mathrm{H}_{2}\right) \gtrsim 8$ $\times 10^{6} \mathrm{~cm}^{-3}$.

Lines of $\mathrm{CH}_{3} \mathrm{C}_{2} \mathrm{H}$ are also weak, but for this molecule the excitation temperature is somewhat lower, $T_{\mathrm{ROT}} \approx 70 \pm 25 \mathrm{~K}$. The derived column density is rather uncertain, being $N\left(\mathrm{CH}_{3} \mathrm{C}_{2} \mathrm{H}\right) \approx(1.3 \pm 1.0) \times 10^{14} \mathrm{~cm}^{-2}$.

In contrast with formaldehyde, the lines of ketene $\left(\mathrm{CH}_{2} \mathrm{CO}\right)$ 


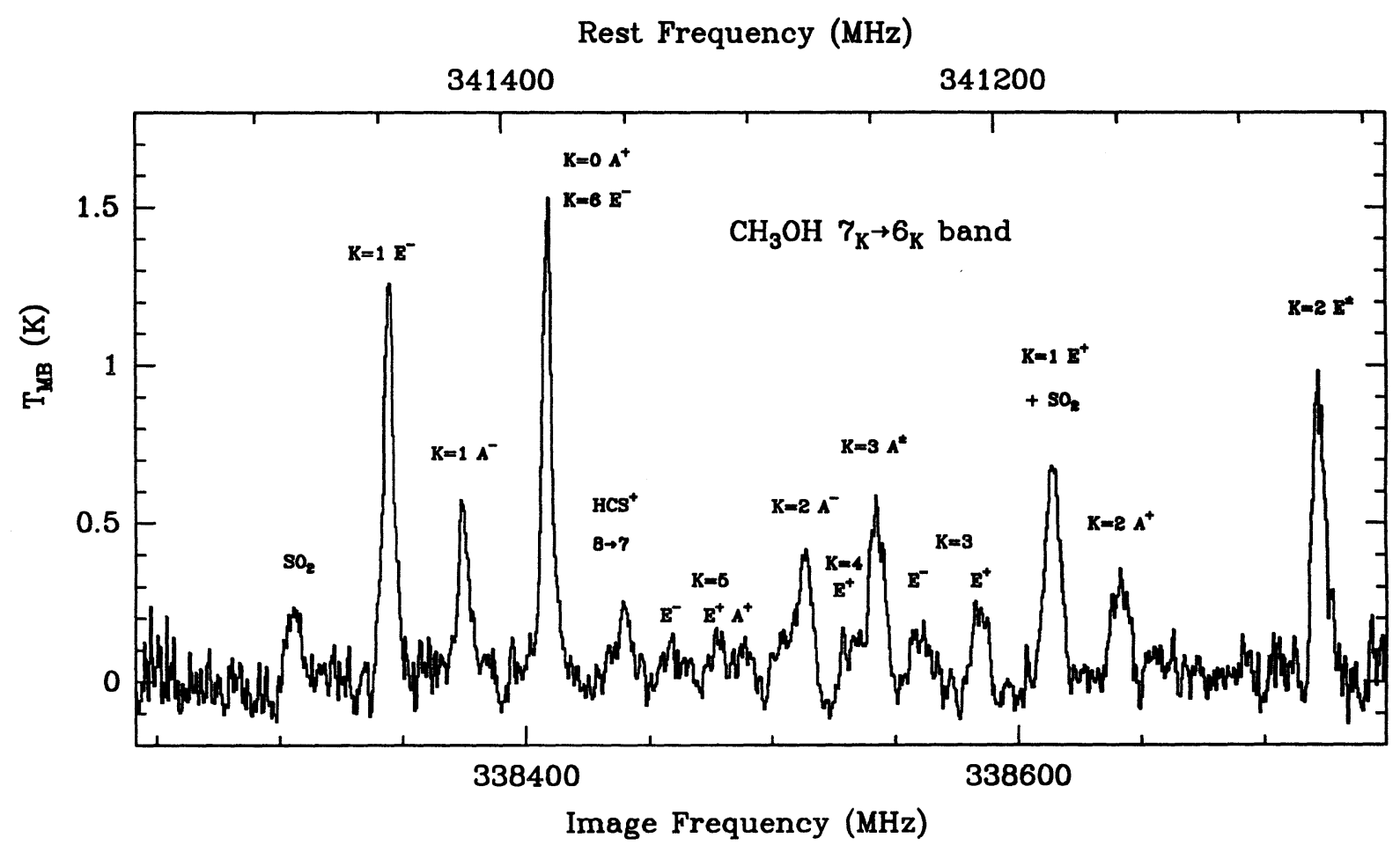

Fig. 10.- CSO spectrum near $338.5 \mathrm{GHz}$ (LSB), which contains the $\mathrm{CH}_{3} \mathrm{OH} 7_{K}-6_{\mathrm{K}}$ band. Also visible are lines of $\mathrm{SO}_{2}$ and $\mathrm{HCS}^{+}$.

are very weak toward IRAS $16293-2422$. Each individual line listed in Table 4 is only a 2-3 $\sigma$ detection, but together they form a likely identification of this molecule. The rotation diagram gives a formal fit of $T_{\mathrm{ROT}} \approx 35 \pm 20 \mathrm{~K}$ and a poorly constrained column density of $N\left(\mathrm{CH}_{2} \mathrm{CO}\right) \approx 4 \times 10^{13} \mathrm{~cm}^{-2}$.

Several lines due to HNCO have been detected as well. Those belonging to the $11_{K}-10_{K}$ transition are blended with the $\mathrm{CH}_{3} \mathrm{OH} 5_{K}-4_{K}$ band, hampering the analysis. The rotation diagram gives $T_{\mathrm{ROT}}=135 \pm 40 \quad \mathrm{~K}$ and

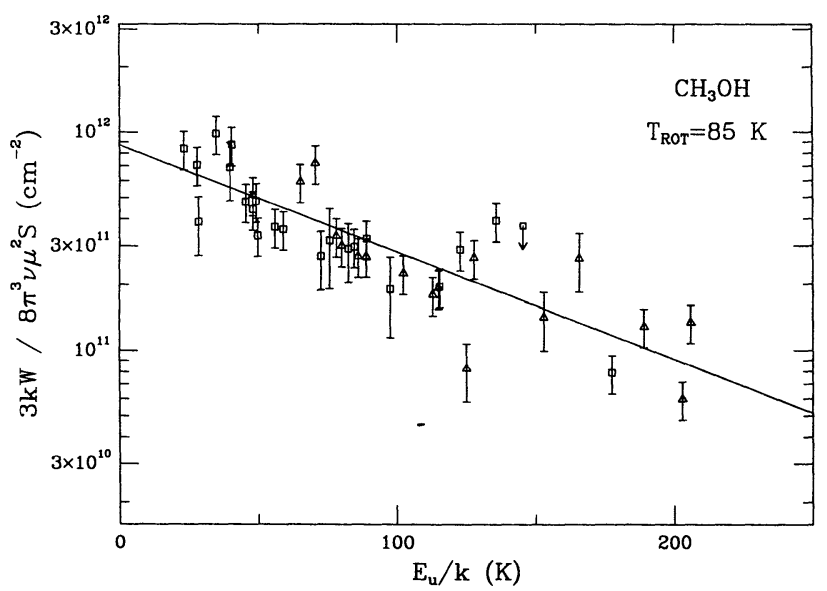

Fig. 11.-Rotation diagram plots of the CSO/JCMT data for $\mathrm{CH}_{3} \mathrm{OH}$. The JCMT data points are presented as squares, while the CSO data are labeled with triangles. The error bars are $20 \%$ of the line intensities, or $30 \%$ in the case of the weakest lines. Upper limits are denoted by arrows.
$N($ HNCO $)=(3.4 \pm 1.5) \times 10^{13} \mathrm{~cm}^{-2}$. No reliable source sizes can be derived for any of these molecules.

\section{5. $\mathrm{CN}, \mathrm{C}_{2} \mathrm{H}$, and $\mathrm{C}_{3} \mathrm{H}_{2}$}

The observed lines of the radicals $\mathrm{CN}, \mathrm{C}_{2} \mathrm{H}$, and $\mathrm{C}_{3} \mathrm{H}_{2}$ are summarized in Table 5 and illustrated in Figures 14 and 15. It is seen that their line widths measured with the JCMT are only $\Delta V \approx 1-2 \mathrm{~km} \mathrm{~s}^{-1}$, considerably smaller than those of other species. This is also reflected in their very low excitation temperatures: $T_{\text {ROT }}(C N) \approx 15 \pm 7 \mathrm{~K}, T_{\text {ROT }}\left(\mathrm{C}_{2} \mathrm{H}\right) \approx 18 \pm 6 \mathrm{~K}$, and $T_{\mathrm{ROT}}\left(\mathrm{C}_{3} \mathrm{H}_{2}\right) \approx 15 \pm 5 \mathrm{~K}$, although these numbers are rather uncertain for $\mathrm{CN}$ and $\mathrm{C}_{2} \mathrm{H}$ for which only two well-separated points are available in the rotation diagram.

For all three species, statistical equilibrium calculations have been performed. The resulting plots are shown in Figure 16. The observed data are seen to be consistent with a density of $n\left(\mathrm{H}_{2}\right) \approx\left(5 \times 10^{5}\right)-\left(2 \times 10^{6}\right) \mathrm{cm}^{-3}$. The inferred column densities are uncertain, especially for $\mathrm{C}_{3} \mathrm{H}_{2}$. The large discrepancy between the rotation diagram value and the statistical equilibrium calculations for this molecule stems from the fact that it has a very large dipole moment, resulting in highly subthermal excitation. No diagnostics of the extent of the emission are available for these species.

\subsection{Deuterated Species}

A large variety of deuterated molecules have been detected toward IRAS $16293-2422$, as summarized in Table 6. DCO ${ }^{+}$ has the strongest lines and is seen not only in the 3-2 line presented in Figure 17, but also in the 5-4 line. These two lines give an excitation temperature of $T_{\text {ROT }}<20 \pm 5 \mathrm{~K}$, where the upper limit stems from the fact that the JCMT beam at 360 $\mathrm{GHz}$ is smaller than that at $216 \mathrm{GHz}$. Statistical equilibrium 

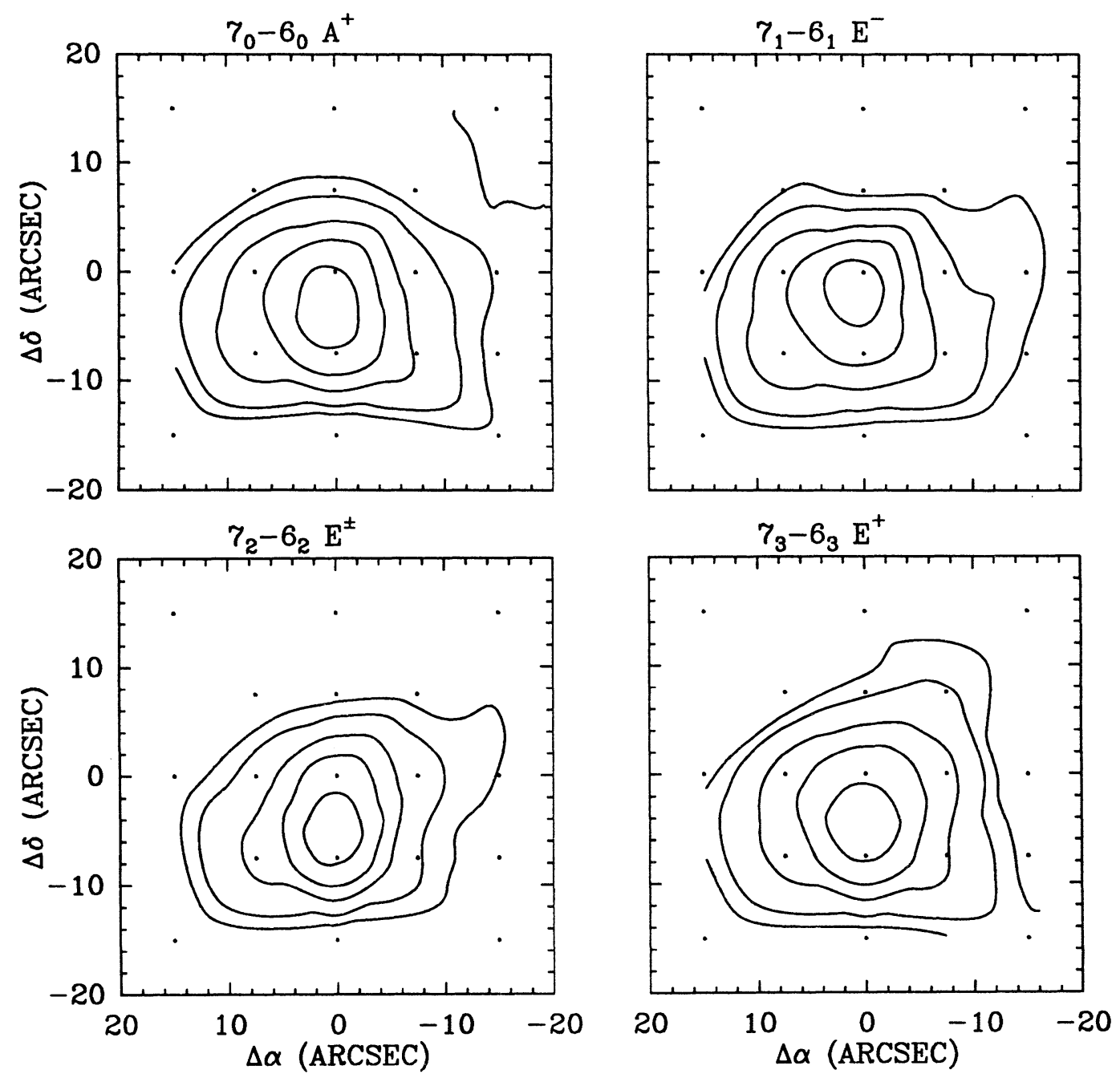

FIG. 12.-Maps of the integrated intensity of various $\mathrm{CH}_{3} \mathrm{OH}$ lines near $338.5 \mathrm{GHz}$ obtained with the JCMT. The contours are at $20 \%$, $30 \%, 50 \%$, $70 \%$, and $90 \%$ of the maximum values, which are $10.8\left(7_{0}-6_{0} A^{+}\right), 8.8\left(7_{1}-6_{1} E^{-}\right), 9.0\left(7_{2}-6_{2} E^{ \pm}\right)$, and $8.5\left(7_{3}-6_{3} E^{+}\right) \mathrm{K} \mathrm{km} \mathrm{s}^{-1}$, respectively.

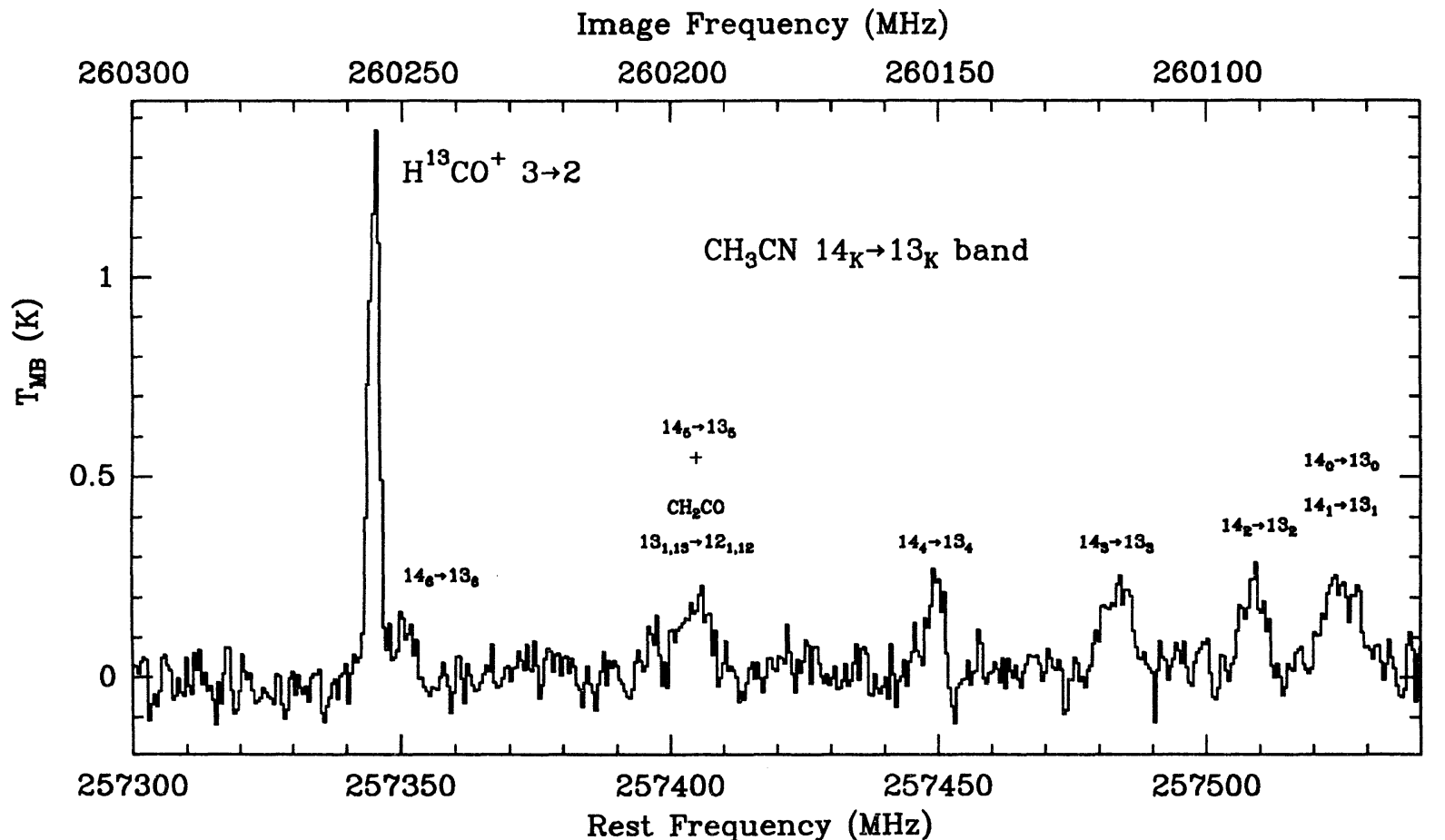

FIG. 13. - JCMT spectrum near $257.4 \mathrm{GHz}$ (LSB), which contains the $\mathrm{CH}_{3} \mathrm{CN} 14_{K}-13_{K}$ band. The $14_{5}-13_{5}$ line is blended with a line of $\mathrm{CH}_{2} \mathrm{CO}$. Also visible is the $\mathrm{H}^{13} \mathrm{CO}^{+}$3-2 line. Note the broad profiles of the $\mathrm{CH}_{3} \mathrm{CN}$ lines compared with those of other species. 
TABLE 4

Observations of $\mathrm{CH}_{3} \mathrm{CN}, \mathrm{CH}_{3} \mathrm{CCH}, \mathrm{HNCO}$, AND $\mathrm{CH}_{2} \mathrm{CO}$

\begin{tabular}{|c|c|c|c|c|c|}
\hline $\begin{array}{l}\text { Molecule } \\
\text { and Line }\end{array}$ & $\begin{array}{l}\text { Frequency } \\
(\mathbf{M H z})\end{array}$ & $\underset{\left(\mathrm{K} \mathrm{km} \mathrm{s}^{-1}\right)}{T_{\mathrm{MB}} d V}$ & $\begin{array}{l}T_{\mathrm{MB}} \\
(\mathrm{K})\end{array}$ & $\begin{array}{c}\Delta V \\
\left(\mathrm{~km} \mathrm{~s}^{-1}\right)\end{array}$ & Telescope \\
\hline 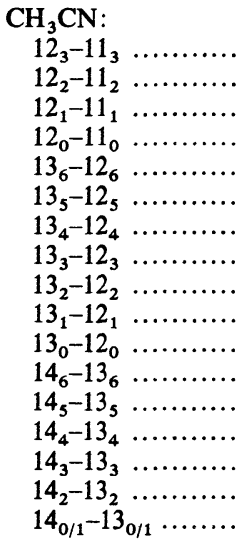 & $\begin{array}{l}220709.0 \\
220730.3 \\
220743.0 \\
220747.3 \\
238972.4 \\
239022.9 \\
239064.3 \\
239096.5 \\
239119.5 \\
239133.3 \\
239137.9 \\
257349.2 \\
257403.6 \\
257448.1 \\
257482.8 \\
257507.6 \\
257527 / 257522\end{array}$ & $\begin{array}{c}\ldots \\
\ldots \\
\ldots \\
\ldots \\
\ldots \\
0.98 \\
\ldots \\
\ldots \\
\ldots \\
\ldots \\
\ldots .58 \\
1.82 \\
1.02 \\
1.85 \\
1.49 \\
2.56\end{array}$ & $\begin{array}{r}\leq 0.29 \\
0.29: \\
0.43: \\
0.43: \\
\leq 0.11 \\
0.14 \\
0.09: \\
0.11: \\
0.11: \\
0.11: \\
0.15: \\
0.14 \\
0.17 \\
0.25 \\
0.24 \\
0.24 \\
0.24\end{array}$ & $\begin{array}{c}\ldots \\
\ldots \\
\ldots \\
\ldots \\
\ldots \\
6.22 \\
\ldots \\
\ldots \\
\ldots \\
\ldots \\
\ldots \\
3.88 \\
10.0: \\
3.67 \\
7.64 \\
5.85 \\
10.3:\end{array}$ & 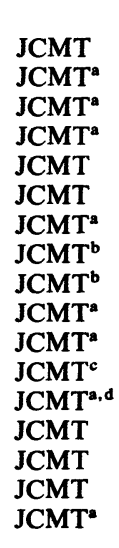 \\
\hline $\begin{aligned} \mathrm{CH}_{3} \mathrm{CCH}: & \\
13_{3}-12_{3} & \ldots \ldots \ldots \ldots \\
13_{2}-12_{2} & \ldots \ldots \ldots \ldots \\
13_{1}-12_{1} & \ldots \ldots \ldots \ldots \\
13_{0}-12_{0} & \ldots \ldots \ldots \ldots \\
14_{0}-13_{0} & \ldots \ldots \ldots \ldots \\
15_{3}-14_{3} & \ldots \ldots \ldots \ldots \\
15_{2}-14_{2} & \ldots \ldots \ldots \ldots \\
15_{1}-14_{1} & \ldots \ldots \ldots \ldots \\
15_{0}-14_{0} & \ldots \ldots \ldots \ldots\end{aligned}$ & $\begin{array}{l}222128.8 \\
222150.0 \\
222162.7 \\
222167.0 \\
239252.3 \\
256292.6 \\
256317.1 \\
256331.8 \\
256336.6\end{array}$ & $\begin{array}{l}\cdots \\
\cdots \\
\cdots \\
\cdots \\
\cdots \\
\cdots \\
\cdots \\
\cdots \\
\cdots\end{array}$ & $\begin{array}{r}0.15: \\
0.13: \\
0.16: \\
0.16: \\
\leq 0.18 \\
0.11: \\
\leq 0.13 \\
\leq 0.13 \\
0.13:\end{array}$ & $\begin{array}{l}\cdots \\
\cdots \\
\cdots \\
\cdots \\
\cdots \\
\cdots \\
\cdots \\
\cdots \\
\cdots\end{array}$ & 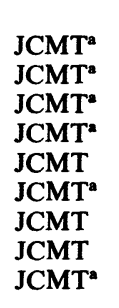 \\
\hline $\begin{array}{l}\mathrm{CH}_{2} \mathrm{CO}: \\
11_{0,11}-10_{0,10} \ldots \ldots . \\
12_{1,12}-11_{1,11} \ldots \ldots \\
12_{0,12}-11_{0,11} \ldots \ldots . \\
12_{1,11}-11_{1,10} \ldots \ldots \\
13_{1,13}-12_{1,12} \ldots \ldots \\
17_{1,17}-16_{1,16} \ldots \ldots\end{array}$ & $\begin{array}{l}222197.7 \\
240185.8 \\
242375.8 \\
244712.2 \\
260192.0 \\
340289.7\end{array}$ & $\begin{array}{c}\ldots .73 \\
\ldots \\
\cdots \\
\ldots \\
0.60\end{array}$ & $\begin{array}{l}0.09: \\
0.15 \\
0.13: \\
0.20 \\
0.15: \\
0.15\end{array}$ & $\begin{array}{l}\ddot{4.4} \\
\ddot{3}: \\
\ddot{3} .91\end{array}$ & $\begin{array}{l}\text { JCMT }^{a} \\
\text { JCMT } \\
\text { JCMTa }^{\mathbf{a}} \\
\text { JCMT }^{\mathrm{a}, \mathrm{e}} \\
\text { JCMT }^{\mathrm{a}, \mathrm{f}} \\
\text { CSO }\end{array}$ \\
\hline 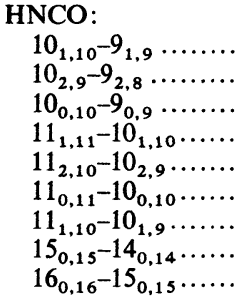 & $\begin{array}{l}218981.0 \\
219733.8 \\
219798.3 \\
240875.7 \\
241703.8 \\
241774.0 \\
242639.7 \\
329664.0 \\
351633.5\end{array}$ & $\begin{array}{c}\cdots \\
\cdots \\
\cdots \\
0.69 \\
\cdots \\
\cdots \\
\ldots .93 \\
\cdots\end{array}$ & $\begin{array}{r}0.07: \\
\leq 0.36 \\
0.36 \\
0.11 \\
0.06: \\
0.25 \\
0.13: \\
0.30 \\
\leq 0.12\end{array}$ & $\begin{array}{l}\ldots \\
\ldots \\
\ldots \\
5.99 \\
\ldots \\
5: \\
\ldots \\
2.88 \\
\ldots\end{array}$ & $\begin{array}{l}\text { JCMT }^{\mathrm{a}} \\
\text { JCMT } \\
\text { JCMTª }^{\mathbf{a}} \\
\text { JCMT } \\
\text { JCMT }^{\mathrm{a}, \mathrm{g}} \\
\text { JCMT }^{\mathrm{a}, \mathrm{e}} \\
\text { JCMT }^{\mathrm{a}} \\
\text { CSO } \\
\text { CSO }\end{array}$ \\
\hline $\begin{array}{l}\mathrm{H}^{15} \mathrm{NCO}: \\
10_{0,10^{-9}}, \ldots \ldots \ldots\end{array}$ & 213216.7 & $\ldots$ & $\leq 0.09$ & $\cdots$ & JCMT \\
\hline
\end{tabular}

a Colon indicates uncertain value.

b Blend with $\mathrm{CH}_{3} \mathrm{OH}$.

${ }^{c}$ On wing of $\mathrm{H}^{13} \mathrm{CO}^{+} 3-2$

d Blend with $\mathrm{CH}_{2} \mathrm{CO}$.

e $\mathrm{On} \mathrm{CH}_{3} \mathrm{OH}$ wing.

${ }^{f}$ Blend with $\mathrm{CH}_{3} \mathrm{CN} 14_{5}-13_{5}$.

${ }^{8}$ Blend with $\mathrm{CH}_{3} \mathrm{OH}$.

calculations (see Fig. 3) indicate that $\mathrm{DCO}^{+}$resides in a region with $n \approx\left(5 \times 10^{5}\right)-\left(3 \times 10^{6}\right) \mathrm{cm}^{-3}$, where the range reflects the uncertainty in the observed ratio due to different beam sizes and to the different widths of the two observed lines. This density is somewhat higher than that derived by Wootten \& Loren (1987) from the lower excitation lines. The derived $\mathrm{DCO}^{+} / \mathrm{H}^{13} \mathrm{CO}^{+}$column density ratio of $\sim 2$ is also substantially higher than the ratio of $\leq 0.28$ found by Wootten \& Loren (1987) at the IRAS position in a larger beam.
Both DCN and DNC are detected in the 3-2, 4-3, and/or 5-4 lines and also appear to have low excitation temperatures, $T_{\mathrm{ROT}}(\mathrm{DCN}) \approx 15 \pm 5 \mathrm{~K}$ and $T_{\mathrm{ROT}}(\mathrm{DNC}) \approx 12 \pm 4 \mathrm{~K}$. The statistical equilibrium calculations for DCN indicate a high density $n\left(\mathrm{H}_{2}\right) \approx 10^{6}-10^{7} \mathrm{~cm}^{-3}$, however (see Fig. 3).

The most important deuterated species observed toward IRAS $16293-2422$ is HDO, the only easily observable tracer of water that can be searched for in this source apart from $\mathrm{H}_{2} \mathrm{O}$ maser emission (Terebey et al. 1992). The $2_{11}-2_{12}$ line at 
TABLE 5

Observations of $\mathrm{CN}, \mathrm{CCH}$, AND $\mathrm{C}_{3} \mathrm{H}_{2}$

\begin{tabular}{|c|c|c|c|c|c|}
\hline $\begin{array}{l}\text { Molecule } \\
\text { and Line }\end{array}$ & $\begin{array}{c}\text { Frequency } \\
(\mathrm{MHz})\end{array}$ & $\int_{\left(\mathrm{K} \mathrm{km} \mathrm{s}^{-1}\right)} T_{\mathrm{MB}} d V$ & $\begin{array}{l}T_{\mathrm{MB}} \\
(\mathrm{K})\end{array}$ & $\begin{array}{c}\Delta V \\
\left(\mathrm{~km} \mathrm{~s}^{-1}\right)\end{array}$ & Telescope \\
\hline \multicolumn{6}{|l|}{$\mathrm{CN}:$} \\
\hline $2, \frac{5}{2}, \frac{5}{2}-1, \frac{3}{2}, \frac{3}{2} \ldots \ldots \ldots$ & 226874.2 & 0.76 & 0.58 & 1.23 & JCMT \\
\hline $2, \frac{5}{2}, \frac{7}{2}-1, \frac{3}{2}, \frac{5}{2} \ldots \ldots \ldots$ & 226874.8 & 0.58 & 0.58 & 0.95 & JCMT \\
\hline $2, \frac{5}{2}, \frac{3}{2}-1, \frac{3}{2}, \frac{1}{2} \ldots \ldots \ldots$ & 226875.9 & $\ldots$ & 0.22 : & $\ldots$ & $\mathrm{JCMT}^{\mathrm{a}}$ \\
\hline $2, \frac{5}{2}, \frac{3}{2}-1, \frac{3}{2}, \frac{3}{2} \ldots \ldots \ldots$ & 226887.4 & $\ldots$ & 0.18 : & $\ldots$ & $\mathrm{JCMT}^{\mathrm{a}}$ \\
\hline $2, \frac{5}{2}, \frac{5}{2}-1, \frac{3}{2}, \frac{5}{2} \ldots \ldots \ldots$ & 226892.2 & $\ldots$ & 0.36 : & $\ldots$ & $\mathrm{JCMT}^{\mathrm{a}}$ \\
\hline $3, \frac{5}{2}, \frac{3}{2}-2, \frac{3}{2}, \frac{1}{2} \ldots \ldots \ldots$ & 340035.4 & 2.77 & 0.50 & 5.04 & $\mathrm{CSO}^{\mathrm{b}}$ \\
\hline $3, \frac{7}{2}, \frac{9}{2}-2, \frac{5}{2}, \frac{7}{2} \ldots \ldots \ldots$ & 340247.8 & 2.95 & 0.73 & 3.84 & CSO \\
\hline \multicolumn{6}{|l|}{$\mathrm{CCH}:$} \\
\hline $3, \frac{7}{2}, 4-2, \frac{5}{2}, 3 \ldots \ldots \ldots \ldots$ & 262004.5 & 3.16 & 1.05 & 2.85 & $\mathrm{JCMT}^{\mathrm{b}}$ \\
\hline $3, \frac{7}{2}, 3-2, \frac{5}{2}, 2 \ldots \ldots \ldots$ & 262006.7 & 0.78 & 0.60 & 1.22 & $\mathrm{JCMT}^{\mathrm{b}}$ \\
\hline $3, \frac{5}{2}, 3-2, \frac{3}{2}, 2 \ldots \ldots \ldots$ & 262065.2 & 1.93 & 0.73 & 2.48 & $\mathrm{JCMT}^{\mathrm{b}}$ \\
\hline $3, \frac{5}{2}, 2-2, \frac{3}{2}, 1 \ldots \ldots \ldots$ & 262067.6 & 0.91 & 0.55 & 1.59 & $\mathrm{JCMT}^{\mathrm{b}}$ \\
\hline $3, \frac{5}{2}, 2-2, \frac{3}{2}, 2 \ldots \ldots \ldots \ldots$ & 262079.1 & $\ldots$ & 0.09: & $\ldots$ & $\mathrm{JCMT}^{\mathrm{a}}$ \\
\hline $3, \frac{5}{2}, 3-2, \frac{3}{2}, 3 \ldots \ldots \ldots$ & 262208.8 & $\ldots$ & $\leq 0.09$ & $\ldots$ & JCMT \\
\hline $4, \frac{9}{2}, 4 / 5-3, \frac{7}{2}, 3 / 4 \ldots \ldots$ & 349338 & 3.27 & 0.95 & 3.2 & CSO \\
\hline $4, \frac{7}{2}, 3 / 4-3, \frac{5}{2}, 2 / 3 \ldots \ldots$ & 349393 & 2.10 & 0.57 & 3.43 & CSO \\
\hline \multicolumn{6}{|l|}{$\mathrm{C}_{3} \mathrm{H}_{2}$ : } \\
\hline $3_{30}-2, \ldots \ldots$ & 216278.8 & 0.96 & 0.56 & 1.61 & JCMT \\
\hline $3_{31}-2_{02} \ldots \ldots \ldots \ldots \ldots \ldots$ & 261831.8 & $\ldots$ & 0.09: & $\ldots$ & $\mathrm{JCMT}^{\mathrm{a}, \mathrm{c}}$ \\
\hline $4_{32}-3_{21} \ldots \ldots \ldots \ldots \ldots \ldots$ & 227169.1 & 0.56 & 0.36 & 1.45 & JCMT \\
\hline $5_{23}-4_{32} \ldots \ldots \ldots \ldots \ldots$ & 249054.4 & 0.51 & 0.13 & 3.52: & JCMT \\
\hline $5_{24}-4_{13} \ldots \ldots \ldots \ldots \ldots \ldots$ & 218160.5 & 0.36 & 0.18 & 1.93 & JCMT \\
\hline $5_{32}-4_{41} \ldots \ldots \ldots \ldots \ldots$ & 260479.7 & $\ldots$ & $\leq 0.18$ & $\ldots$ & JCMT \\
\hline $5_{50}-4_{41} \ldots \ldots \ldots \ldots \ldots \ldots$ & 349264.0 & 0.28 & 0.15 & 1.91 & CSO \\
\hline $5_{51}-4_{40} \ldots \ldots \ldots \ldots \ldots$ & 338204.0 & $\ldots$ & $0.13:$ & $\ldots$ & $\mathrm{JCMT}^{\mathrm{a}}$ \\
\hline $8_{26}-7_{35} \ldots \ldots \ldots \ldots \ldots$ & 352185.4 & $\ldots$ & $\leq 0.12$ & $\ldots$ & CSO \\
\hline $8_{36}-7_{25} \ldots \ldots \ldots \ldots \ldots$ & 352193.5 & 1.05 & $.20:$ & 5.0: & $\mathrm{CSO}$ \\
\hline $8_{36}-8_{27} \ldots \ldots \ldots \ldots \ldots$ & 218449.4 & $\ldots$ & $\leq 0.07$ & $\ldots$ & JCMT \\
\hline $9_{1 / 2,8}-8_{2 / 1,7} \ldots \ldots \ldots \ldots$ & 351965.8 & 0.85 & $0.25:$ & 3.2: & $\mathrm{CSO}^{\mathrm{a}}$ \\
\hline $10_{0 / 1,10^{-9}} 9_{1 / 0,9} \ldots \ldots \ldots \ldots$ & 351781.5 & $\ldots$ & $\leq 0.12$ & $\ldots$ & CSO \\
\hline $11_{5,6}-11_{4,7} \ldots \ldots \ldots \ldots$ & 216808.8 & $\ldots$ & $\leq 0.07$ & $\ldots$ & JCMT \\
\hline $11_{6,6}-11_{5,7} \ldots \ldots \ldots \ldots \ldots$ & 216845.7 & $\ldots$ & $\leq 0.07$ & $\ldots$ & JCMT \\
\hline
\end{tabular}

a Colon indicates uncertain value.

b Blend.

${ }^{c}$ On SO wing.

$241561 \mathrm{MHz}$ has been detected at the $2 \sigma$ level at both the JCMT and the CSO. Statistical equilibrium calculations have been performed for HDO including excitation due to farinfrared radiation by dust at $T_{d} \approx 40 \mathrm{~K}$ (Mezger et al. 1992). For $T_{\text {kin }} \approx 40-80 \mathrm{~K}$ and $n\left(\mathrm{H}_{2}\right) \approx(0.5-1) \times 10^{7} \mathrm{~cm}^{-3}$, the inferred column density is $N($ HDO $) \approx\left(1_{-0.5}^{+1}\right) \times 10^{15} \mathrm{~cm}^{-2}$.

Several lines of deuterated formaldehyde HDCO, are readily detected, as illustrated in Figure 18. They are characterized by $T_{\mathrm{ROT}} \approx 55 \pm 20 \mathrm{~K}$ and imply a substantial column density, $N($ HDCO $) \approx 2 \times 10^{13} \mathrm{~cm}^{-2}$. Two weak lines of HDS have also been detected at the JCMT (see Fig. 9), suggesting $T_{\text {ROT }} \approx$ $12 \pm 4 \mathrm{~K}$ and a column density of $N(\mathrm{HDS}) \approx 3 \times 10^{13} \mathrm{~cm}^{-2}$.

Deuterated ammonia, $\mathrm{NH}_{2} \mathrm{D}$, has been observed via its ground $1_{01}-0_{00}$ near $333 \mathrm{GHz}$ and possibly the higher lying $3_{22}-3_{12}$ transition near $216 \mathrm{GHz}$, although the latter line is blended with a possible $\mathrm{C}_{2} \mathrm{H}_{5} \mathrm{OH}$ feature. If all of the $216 \mathrm{GHz}$ emission is ascribed to $\mathrm{NH}_{2} \mathrm{D}$, the implied rotational temperature $T_{\text {ROT }} \approx 25 \pm 5 \mathrm{~K}$. The absence of $\mathrm{NH}_{2} \mathrm{D}$ emission at $239.8 \mathrm{GHz}$ suggests that the excitation temperature is probably somewhat lower. Detection of deuterated methanol $\mathrm{CH}_{3} \mathrm{OD}$ is less certain, and the derived column density $N\left(\mathrm{CH}_{3} \mathrm{OD}\right)<8$ $\times 10^{12} \mathrm{~cm}^{-2}$ should be regarded as an upper limit. Finally, two features due to CCD are unmistakenly present in Figure 17 , implying a column density $N(C C D) \approx 9 \times 10^{12} \mathrm{~cm}^{-2}$.

\subsection{Other Molecules}

Upper limits on the strongest lines of other molecules covered in our data set are listed in Table 7. Most significant are the nondetections of $\mathrm{H}_{3} \mathrm{O}^{+}$by Phillips, van Dishoeck, \& Keene (1992) and of more complex organic species such as $\mathrm{CH}_{3}$ CHO. The $\mathrm{H}_{3} \mathrm{O}^{+}$limit of $\mathrm{T}_{\mathrm{MB}}<0.13 \mathrm{~K}$ for the $396 \mathrm{GHz}$ line implies an upper limit on the $\mathrm{H}_{3} \mathrm{O}^{+}$column density of less than $4 \times 10^{13} \mathrm{~cm}^{-2}$, assuming $T_{\text {kin }}=50-100 \mathrm{~K}$ and $n\left(\mathrm{H}_{2}\right)=$ $10^{6}-10^{7} \mathrm{~cm}^{-3}$. The $\mathrm{H}_{3} \mathrm{O}^{+}$column density can be used to place an indirect limit on the $\mathrm{H}_{2} \mathrm{O}$ column density. The simple analysis of the gas-phase oxygen chemistry discussed by Phillips et al. (1992) indicates $N\left(\mathrm{H}_{2} \mathrm{O}\right) / N\left(\mathrm{H}_{3} \mathrm{O}^{+}\right) \approx 1000$, whereas more detailed chemical models give values between 500-2000. If the larger ratio of 2000 is adopted, $N\left(\mathrm{H}_{2} \mathrm{O}\right)<10^{17} \mathrm{~cm}^{-2}$ is derived. The same limit is obtained if most of the $\mathrm{H}_{2} \mathrm{O}$ is assumed to be produced by surface reactions on grains and 


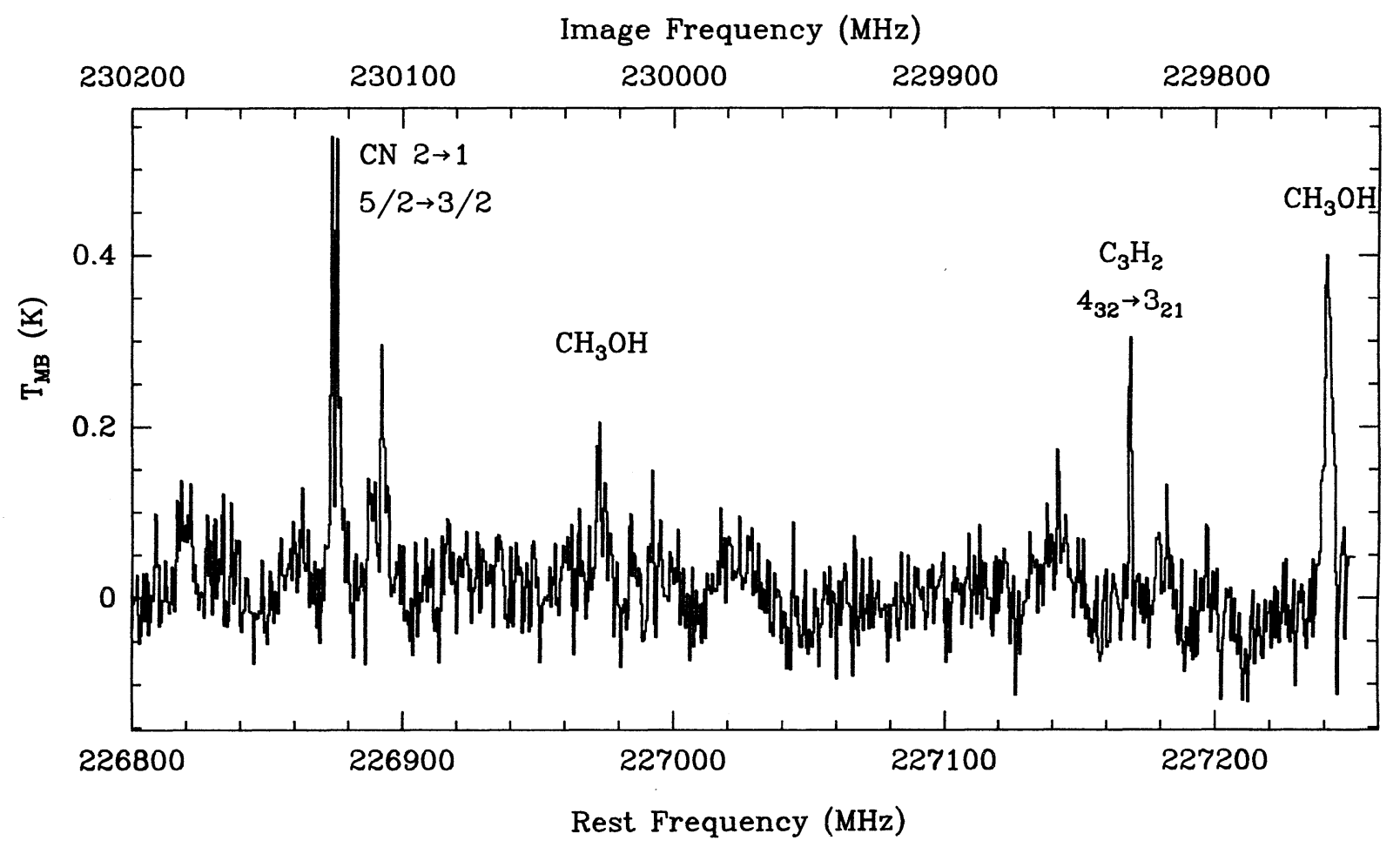

Fig. 14.-JCMT spectrum near $227.0 \mathrm{GHz}$ (LSB), which contains $\mathrm{CN} 2-1$ lines. Also visible are lines of $\mathrm{CH}_{3} \mathrm{OH}$ and $\mathrm{C}_{3} \mathrm{H}_{2}$. Note the narrow widths of the CN and $\mathrm{C}_{3} \mathrm{H}_{2}$ lines compared with those of other species.

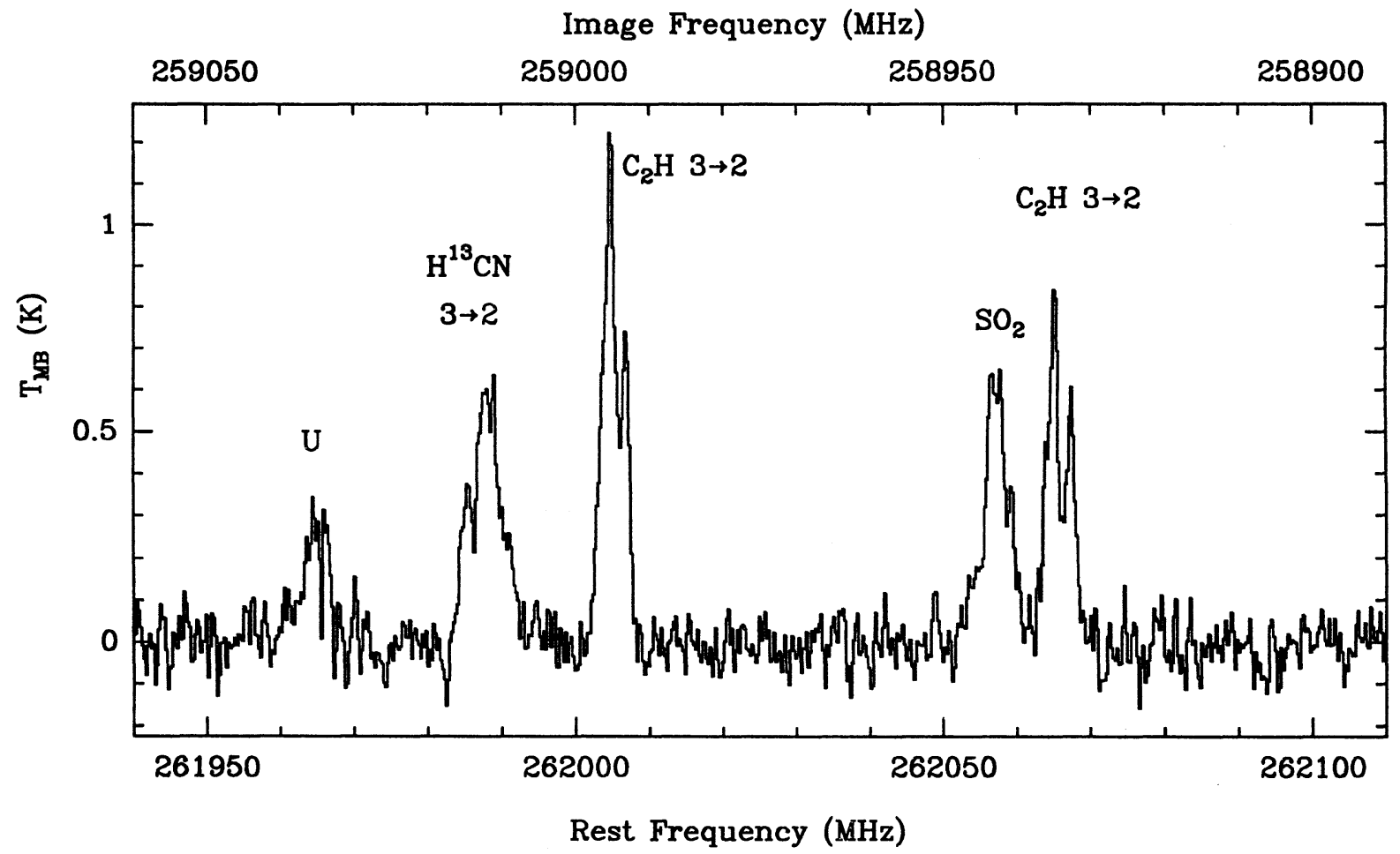

FIG. 15.-JCMT spectrum near $262.0 \mathrm{GHz}$ (USB), which contains the $\mathrm{C}_{2} \mathrm{H}$ 3-2 lines. Also visible are lines of $\mathrm{H}^{13} \mathrm{CN}, \mathrm{SO}_{2}$, and an unidentified line. 

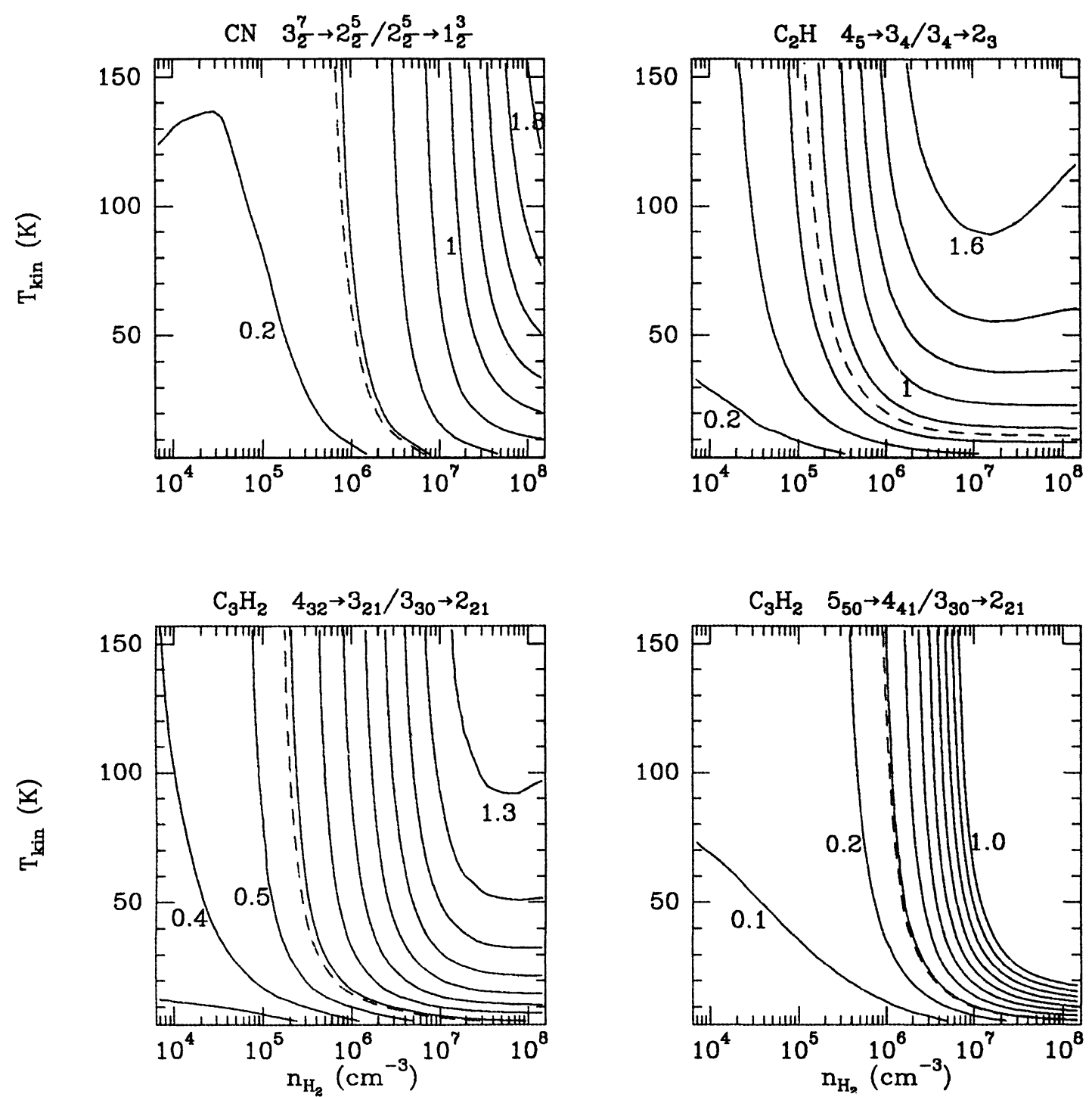

Fig. 16.-Variation of line antenna temperature ratios with kinetic temperature and density obtained from the statistical equilibrium calculations for $\mathrm{CN}_{2} \mathrm{C}_{2} \mathrm{H}$, and $\mathrm{C}_{3} \mathrm{H}_{2}$. The full lines are the model results, and the dashed lines indicate the observed ratios. The contour values are indicated in the plots. The adopted $\mathrm{CN}$ column density is $N=2 \times 10^{13} \mathrm{~cm}^{-2}$ with a line width $\Delta V=1.1 \mathrm{~km} \mathrm{~s}^{-1}$. For $\mathrm{C}_{2} \mathrm{H}$, the adopted $N=5 \times 10^{13} \mathrm{~cm}^{-2}$ with $\Delta V=2 \mathrm{~km} \mathrm{~s}-1$; for ortho- $\mathrm{C}_{3} \mathrm{H}_{2}$, $N=1 \times 10^{13} \mathrm{~cm}^{-2}$ with $\Delta V=1.6 \mathrm{~km} \mathrm{~s}^{-1}$.

subsequently released back into the gas phase where it reacts with $\mathrm{H}_{3}^{+}$to form $\mathrm{H}_{3} \mathrm{O}^{+}$(Phillips et al. 1992).

Some features of ethanol, $\mathrm{C}_{2} \mathrm{H}_{5} \mathrm{OH}$, may be present in the spectra, but unfortunately the strongest lines are blended with lines of $\mathrm{NH}_{2} \mathrm{D}$ (see above) and of $\mathrm{CH}_{3} \mathrm{OH}$. If the tentative features were real, they would imply $N\left(\mathrm{C}_{2} \mathrm{H}_{5} \mathrm{OH}\right) \approx 4 \times 10^{13}$ $\mathrm{cm}^{-2}$, assuming that the excitation temperature of $\mathrm{C}_{2} \mathrm{H}_{5} \mathrm{OH}$ is similar to that of $\mathrm{CH}_{3} \mathrm{OH}$. Upper limits on the column densities of other species have been derived under the assumption that their excitation temperatures are in the range $20-80 \mathrm{~K}$, which covers that found for most other species. For many molecules, this range in excitation temperatures leads to rather stringent limits on the column densities, because the observed lines involve energy levels that lie in the same temperature range. For linear rotors such as $\mathrm{C}_{3} \mathrm{O}, \mathrm{C}_{3} \mathrm{~S}$, and NO, however, as well as for $\mathrm{C}_{2} \mathrm{H}_{3} \mathrm{CN}$, the observed lines in the 230 and 345 $\mathrm{GHz}$ windows have upper levels at greater than $150 \mathrm{~K}$, resulting in much higher limits on the column densities, especially if the excitation temperature were only $20 \mathrm{~K}$. Observations at longer wavelengths would provide a better probe of these species.

\section{DISCUSSION}

\subsection{Physical Structure}

The observations presented in this work demonstrate that regions with different physical conditions are present in our $20^{\prime \prime}$ beam, which corresponds to $\sim 0.015 \mathrm{pc}$ or $3000 \mathrm{AU}$ at a distance of 160 pc. In Paper I, we distinguished at least four different components in IRAS 16293-2422, based on the interferometric and single-dish observations of Mundy et al. (1990, 1992, 1994), Walker, Carlstrom, \& Bieging (1993), and Mezger et al. (1992) (see Fig. 6 of Mundy et al. 1990 for a schematic of the region): (1) two unresolved circumstellar disks $\left[T_{\text {kin }} \approx 40-45 \mathrm{~K}, n\left(\mathrm{H}_{2}\right) \geq 10^{9} \mathrm{~cm}^{-3}\right.$, each of size less than 250 
TABLE 6

Observations of Deuterated Species

\begin{tabular}{|c|c|c|c|c|c|}
\hline $\begin{array}{l}\text { Molecule } \\
\text { and Line }\end{array}$ & $\begin{array}{c}\text { Frequency } \\
\text { (MHz) }\end{array}$ & $\int_{\left(\mathrm{K} \mathrm{km} \mathrm{s}^{-1}\right)} T_{\mathrm{MB}} d V$ & $\begin{array}{l}T_{\mathrm{MB}} \\
(\mathrm{K})\end{array}$ & $\begin{array}{c}\Delta V \\
\left(\mathrm{~km} \mathrm{~s}^{-1}\right)\end{array}$ & Telescope \\
\hline $\begin{array}{l}\mathrm{DCO}^{+}: \\
\quad 3-2 \ldots \ldots \ldots \ldots \ldots \ldots \\
5-4 \ldots \ldots \ldots \ldots \ldots\end{array}$ & $\begin{array}{l}216112.6 \\
360169.9\end{array}$ & $\begin{array}{l}5.18 \\
4.02\end{array}$ & $\begin{array}{l}2.56 \\
1.19\end{array}$ & $\begin{array}{l}1.89 \\
3.16\end{array}$ & $\begin{array}{l}\text { JCMT } \\
\text { JCMT }\end{array}$ \\
\hline $\begin{array}{l}\text { DCN: } \\
\quad 3-2 \ldots \ldots \ldots \ldots \ldots \ldots \\
5-4 \ldots \ldots \ldots \ldots \ldots \ldots\end{array}$ & $\begin{array}{l}217238.5 \\
362046.5\end{array}$ & $\begin{array}{l}4.95 \\
1.02\end{array}$ & $\begin{array}{l}0.80 \\
0.40\end{array}$ & $\begin{array}{l}5.87 \\
2.43\end{array}$ & $\begin{array}{l}\mathrm{JCMT}^{\mathbf{a}} \\
\mathrm{CSO}\end{array}$ \\
\hline $\begin{array}{l}\text { DNC: } \\
\quad 3-2 \ldots \ldots \ldots \ldots \ldots \ldots \\
\quad 4-3 \ldots \ldots \ldots \ldots \ldots \ldots\end{array}$ & $\begin{array}{l}228910.5 \\
305206.0\end{array}$ & $\begin{array}{l}1.23 \\
0.75\end{array}$ & $\begin{array}{l}0.56 \\
0.20\end{array}$ & $\begin{array}{l}2.10 \\
3.45\end{array}$ & $\begin{array}{l}\text { JCMT } \\
\text { JCMT }\end{array}$ \\
\hline 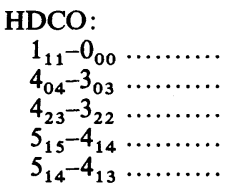 & $\begin{array}{l}227668.1 \\
256585.3 \\
257749.1 \\
308417.9 \\
335096.5\end{array}$ & $\begin{array}{l}3.22 \\
1.39 \\
4.58 \\
3.95\end{array}$ & $\begin{array}{r}\leq 0.43 \\
0.87 \\
0.35 \\
0.81 \\
0.71\end{array}$ & $\begin{array}{l}\ldots \\
3.50 \\
3.79 \\
5.36 \\
5.21\end{array}$ & $\begin{array}{l}\text { JCMT } \\
\text { JCMT } \\
\text { JCMT } \\
\text { JCMT } \\
\text { JCMT }\end{array}$ \\
\hline 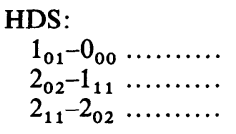 & $\begin{array}{l}244555.6 \\
333278.7 \\
257781.4\end{array}$ & $\begin{array}{c}0.91 \\
\ldots \\
0.16\end{array}$ & $\begin{array}{r}0.13 \\
\leq 0.17 \\
0.13\end{array}$ & $\begin{array}{c}6.64 \\
\ldots \\
1.14:\end{array}$ & $\begin{array}{l}\text { JCMT } \\
\text { CSO } \\
\text { JCMT }^{b}\end{array}$ \\
\hline $\begin{array}{l}\text { HDO: } \\
\qquad 2_{11}-2_{12} \ldots \ldots \ldots \cdots \\
3_{12}-2_{12} \ldots \ldots \cdots \cdots\end{array}$ & $\begin{array}{l}241561.5 \\
225896.7\end{array}$ & $\begin{array}{c}0.62 \\
\cdots\end{array}$ & $\begin{array}{r}0.08 \\
\leq 0.71\end{array}$ & $\begin{array}{c}7.26 \\
\cdots\end{array}$ & $\begin{array}{l}\text { JCMT } \\
\text { JCMT }\end{array}$ \\
\hline $\begin{array}{l}\mathrm{NH}_{2} \mathrm{D}: \\
3_{2214}-3_{1204} \ldots \ldots \\
3_{2203}-3_{1213} \ldots \ldots \\
1_{01}-0_{00} \ldots \ldots \ldots \ldots\end{array}$ & $\begin{array}{l}239848.0 \\
216563.0 \\
332781.8\end{array}$ & $\begin{array}{l}\ldots .22: \\
1.40\end{array}$ & $\begin{array}{c}\leq 0.11 \\
0.09 \\
0.38\end{array}$ & $\begin{array}{l}\cdots \\
2.43 \\
3.41\end{array}$ & $\begin{array}{l}\mathrm{JCMT} \\
\mathrm{JCMT}^{\mathrm{b}, \mathrm{c}} \\
\mathrm{CSO}\end{array}$ \\
\hline $\begin{array}{l}\text { CCD: } \\
\quad 3, \frac{7}{2}-2, \frac{5}{2} \ldots \ldots \ldots \\
\quad 3, \frac{5}{2}-2, \frac{3}{2} \ldots \ldots \ldots\end{array}$ & $\begin{array}{l}216373 \\
216428\end{array}$ & $\begin{array}{l}0.75 \\
0.49\end{array}$ & $\begin{array}{l}0.29 \\
0.22\end{array}$ & $\begin{array}{l}2.48 \\
2.03\end{array}$ & $\begin{array}{l}\text { JCMT } \\
\text { JCMT }^{d}\end{array}$ \\
\hline $\mathrm{CH}_{3} \mathrm{OD}: \ldots \ldots \ldots \ldots$ & 338196 & $\ldots$ & $0.13:$ & $\ldots$ & $\mathbf{J C M T}^{\mathbf{b}}$ \\
\hline $\begin{array}{l}\mathrm{C}_{3} \mathrm{HD}: \\
3_{31}-2_{02} \ldots \ldots \ldots \ldots\end{array}$ & 258076.7 & $\ldots$ & $\leq 0.09$ & $\cdots$ & JCMT \\
\hline
\end{tabular}

a Possibly self-absorbed.

b Colon indicates uncertain value.

c Blend with $\mathrm{H}_{2} \mathrm{CO}$ and $\mathrm{C}_{2} \mathrm{H}_{5} \mathrm{OH}$.

d Blend with $\mathrm{SO}_{2} 26_{3,23}-26_{2,24}$.

Image Frequency $(\mathrm{MHz})$

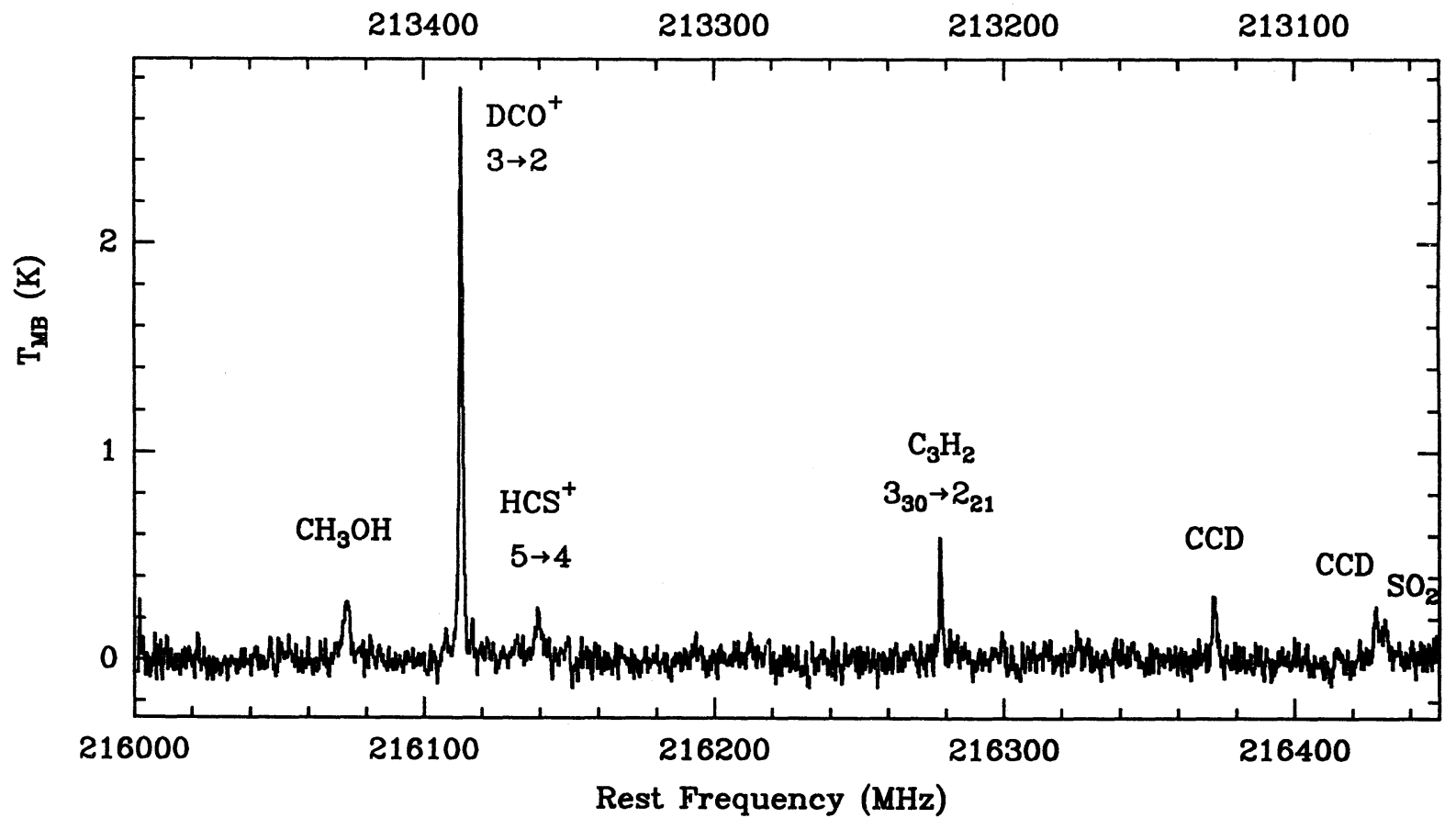

Fig. 17.-JCMT spectrum near $216.0 \mathrm{GHz}$ (USB), which contains the $\mathrm{DCO}^{+} 3-2$ and $\mathrm{CCD}$ lines. Also visible are lines of $\mathrm{CH}_{3} \mathrm{OH}, \mathrm{HCS}^{+}, \mathrm{C}_{3} \mathrm{H}_{2}$, and $\mathrm{SO}_{2}$. 


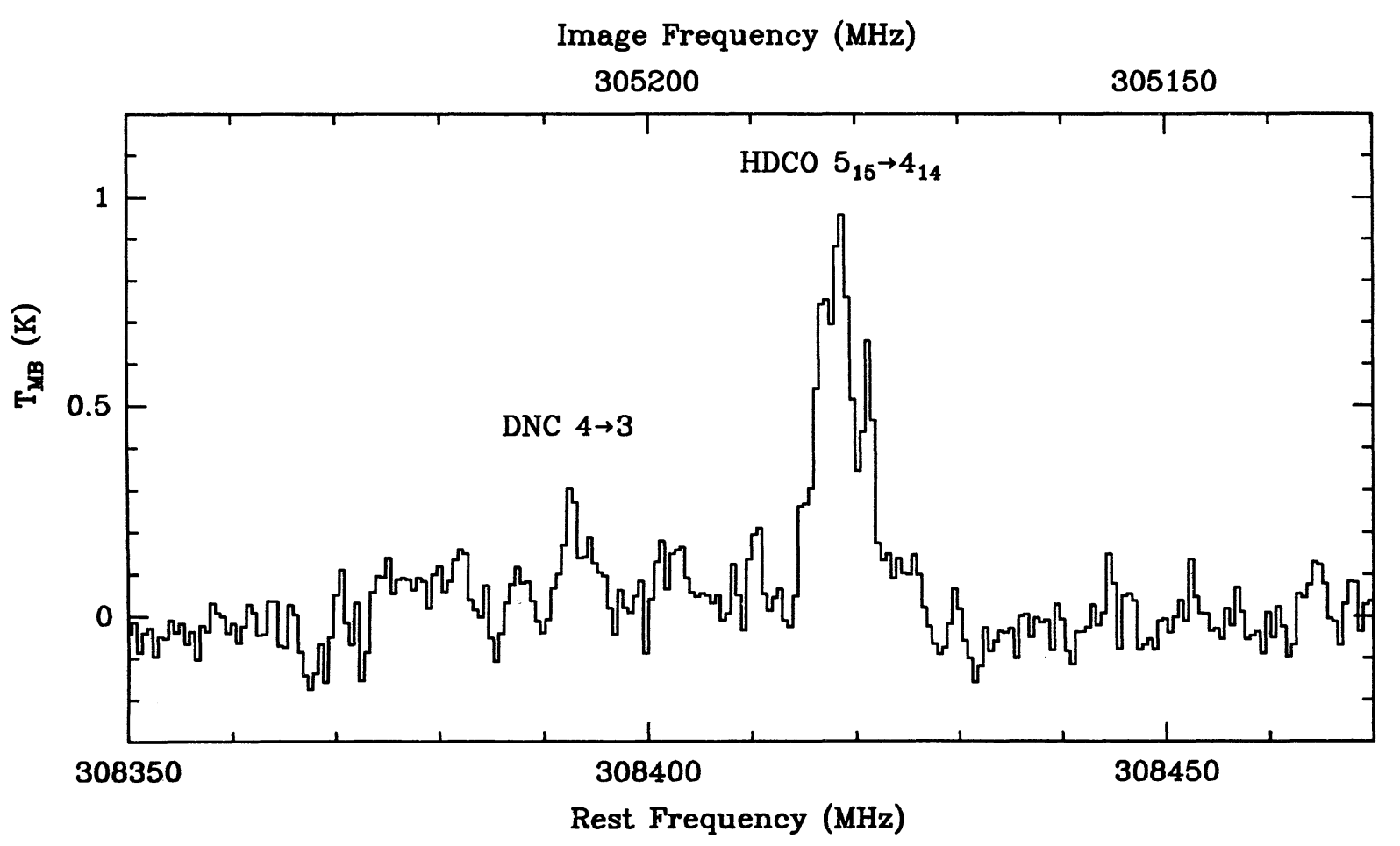

FIG. 18.-JCMT spectrum near 308.4 GHz (USB), which contains lines of the deuterated species HDCO and DNC

AU or less than $\left.1^{\prime \prime} .5\right],(2)$ a circumbinary envelope $\left[T_{\text {kin }} \approx 40 \mathrm{~K}\right.$, $n\left(\mathrm{H}_{2}\right) \approx 10^{6}-10^{7} \mathrm{~cm}^{-3}$, size $\approx 2000 \mathrm{AU}$ or $\left.10^{\prime \prime}-15^{\prime \prime}\right]$, (3) an ambient molecular core $\left[T_{\mathrm{kin}} \approx 15-20 \mathrm{~K}, n\left(\mathrm{H}_{2}\right) \approx\right.$ few $\times 10^{4}$ $\mathrm{cm}^{-3}$, size $\approx 0.1 \mathrm{pc}$ or a few arcminutes], and (4) the outflow component(s). This division into various components is somewhat artificial since gradients in physical conditions are undoubtedly present, especially in the transition from the circumbinary envelope to the ambient cloud. Nevertheless, it provides a useful starting point for the analysis. In the following, we will investigate in which of these components the various molecules reside based on the physical parameters, excitation temperatures, and source sizes derived in $\S 4$.

The S- and Si-bearing molecules were found to probe mostly component 4 , a region of size $500-1500 \mathrm{AU}\left(3^{\prime \prime}-10^{\prime \prime}\right)$ where the bipolar outflow(s) interacts with the inner part of the circumbinary envelope (Paper I). This interaction results in higher temperatures of $T_{\text {kin }} \approx 70-80 \mathrm{~K}$ at densities $n\left(\mathrm{H}_{2}\right) \approx(0.5-1)$ $\times 10^{7} \mathrm{~cm}^{-3}$. The analysis of $\S 4$ clearly indicates that this same component also contains molecules such as $\mathrm{CH}_{3} \mathrm{OH}$ and $\mathrm{H}_{2} \mathrm{CO}$. Indeed, the rotational temperature derived for $\mathrm{CH}_{3} \mathrm{OH}, T_{\mathrm{ROT}} \approx 85 \pm 6 \mathrm{~K}$, is very close to that found for $\mathrm{SO}_{2}$ in Paper $\mathrm{I}, T_{\text {ROT }} \approx 95 \pm 5 \mathrm{~K}$. Even higher temperature gas with $T_{\text {kin }}$ up to $150 \mathrm{~K}$ may be present in this region, as evidenced by the higher excitation $\mathrm{H}_{2} \mathrm{CO}$ lines. Molecules with high rotational temperatures such as $\mathrm{CH}_{3} \mathrm{CN}$ and $\mathrm{HC}_{3} \mathrm{~N}$ presumably reside in the same gas. It should be noted, however, that these organic molecules are probably not the result of direct shock chemistry following grain disruption, like SiO. They are likely to result from the gentler desorption of grain mantle material, perhaps induced by grain-grain collisions in the turbulent velocity shear zones surrounding the outflow axes (Blake et al. 1995; Raga \& Cabrit 1993).

Another difference with, e.g., $\mathrm{SiO}$ is that some of the emis- sion from these organic molecules may also arise from other components in IRAS 16293-2422. In particular, the lower lying $\mathrm{H}_{2} \mathrm{CO}$ lines indicate physical parameters similar to those of the more quiescent circumbinary envelope, component 2. Also, more common species such as $\mathrm{CS}$ and $\mathrm{HCO}^{+}$appear to reside principally in this component, based on their inferred excitation temperature and/or source size.

The outer part of the envelope and the ambient cloud core (component 3) are traced mostly by unsaturated molecules, such as the radicals $\mathrm{C}_{2} \mathrm{H}, \mathrm{C}_{3} \mathrm{H}_{2}$, and $\mathrm{CN}$. These species have very narrow line widths and indicate densities $n\left(\mathrm{H}_{2}\right) \approx 10^{5}-10^{6}$ $\mathrm{cm}^{-3}$ and presumably lower temperatures, although no good constraints are available on the latter in our data set. This component 3 is also seen by Menten et al. (1987) in their lower $J$ CS lines and by Mundy et al. (1990) in $\mathrm{NH}_{3}$ interferometric images as their "outer disk" source with a size of $30^{\prime \prime}-35^{\prime \prime}$ ( $\sim 5000 \mathrm{AU})$. The single-dish $\mathrm{NH}_{3}$ observations of Menten et al. indicate a kinetic temperature of $\sim 40 \mathrm{~K}$ for this gas.

The colder and lower density gas is also visible as selfabsorption in the lines of $\mathrm{CS}, \mathrm{HCN}, \mathrm{HCO}^{+}$, and $\mathrm{H}_{2} \mathrm{CO}$. The observed optical depths are summarized in Table 8. In the analysis, two sets of physical conditions are assumed, either appropriate for the cold ambient cloud with $T \approx 15 \mathrm{~K}$ and $n\left(\mathbf{H}_{2}\right) \approx 3 \times 10^{4} \mathrm{~cm}^{-3}$ (Menten et al. 1987; Wootten \& Loren 1989) or for the outer part of the circumbinary envelope with $T \approx 20 \mathrm{~K}, n\left(\mathrm{H}_{2}\right) \approx 2 \times 10^{5} \mathrm{~cm}^{-3}$. The inferred column densities for these two cases are included in Table 9. In order to probe the ambient cloud, we also observed some emission lines at positions away from the young stellar object(s). Table 9 summarizes the lines searched for at the $120^{\prime \prime}$ south position. Only very few molecules are detected here; even the CS 5-4 line is not seen, suggesting that the density is less than $10^{5}$ $\mathrm{cm}^{-3}$. The resulting upper limits on the column densities are 
TABLE 7

SIGNIFICANT NONDETECTIONS

\begin{tabular}{|c|c|c|c|c|}
\hline Molecule & Line & $\begin{array}{c}\text { Frequency } \\
(\mathrm{MHz})\end{array}$ & $\begin{array}{l}T_{\mathrm{MB}} \\
(\mathrm{K})\end{array}$ & Telescope \\
\hline NO & $3_{2}-2_{2}$ & 257853 & $\leq 0.18$ & JCMT \\
\hline \multirow[t]{2}{*}{$\mathrm{C}_{3} \mathrm{O}$} & $23-22$ & 221262 & $\leq 0.15$ & $\mathrm{JCMT}^{\mathrm{a}}$ \\
\hline & $25-24 \ldots$ & 240494 & $\leq 0.13$ & JCMT \\
\hline \multirow[t]{3}{*}{$\mathrm{C}_{3} \mathrm{~S}$} & $37_{0}-36_{0}$ & 213843 & $\leq 0.07$ & JCMT \\
\hline & $43_{0}-42_{0} \ldots \ldots \ldots \ldots$ & 248501 & $\leq 0.11$ & JCMT \\
\hline & $45_{0}-44_{0} \ldots \ldots \ldots \ldots$ & 260052 & $\leq 0.18$ & JCMT \\
\hline \multirow{5}{*}{$\begin{array}{l}\mathrm{H}_{3} \mathrm{O}^{+} \\
\mathrm{HCO}\end{array}$} & $3_{0}-2_{0} \ldots \ldots \ldots \ldots \ldots$ & 396272 & $\leq 0.17$ & CSO \\
\hline & $10_{0,10, K}-9_{1,9, K} \cdots$ & 241482 & $\leq 0.07$ & JCMT \\
\hline & $3_{2, K}-2_{2, K} \cdots \cdots \cdots$ & 258202 & $\leq 0.09$ & JCMT \\
\hline & $3_{0,3, K}-2_{0,2, K} \cdots \ldots$ & 260060 & $\leq 0.18$ & JCMT \\
\hline & $4_{K}-3_{K} \ldots \ldots \ldots \ldots \ldots$ & 352204 & $\leq 0.11$ & CSO \\
\hline \multirow{4}{*}{$\mathrm{HCOOH}$} & $11_{4,8}-10_{4,7} \ldots \ldots$. & 261216 & $\leq 0.09$ & JCMT \\
\hline & $11_{0,11}-10_{0,10} \cdots$ & 241146 & $\leq 0.15$ & JCMT \\
\hline & $12_{0,12}-11_{0,11} \ldots \ldots$ & 262104 & $\leq 0.09$ & JCMT \\
\hline & $12_{1,12}-11_{1,11} \ldots \ldots$ & 257975 & $\leq 0.09$ & JCMT \\
\hline \multirow[t]{5}{*}{$\mathrm{CH}_{3} \mathrm{CHO}$} & $11_{1,10}-10_{1,9} A \ldots$ & 216630 & $\leq 0.07$ & JCMT \\
\hline & $11_{2,10}-10_{2,9} A \ldots$ & 211240 & $\leq 0.11$ & JCMT \\
\hline & $13_{0,13}-12_{0,12} A \ldots$ & 244827 & $\leq 0.13$ & JCMT \\
\hline & $13_{1,13}-12_{1,12} A \ldots$ & 242113 & $\leq 0.13$ & JCMT \\
\hline & $13_{3,11}-13_{2,12} E \ldots$ & 240431 & $\leq 0.11$ & JCMT \\
\hline \multirow[t]{5}{*}{$\mathrm{C}_{2} \mathrm{H}_{5} \mathrm{OH}$} & $9_{2,8}-8_{1,7} \ldots \ldots \ldots \ldots$ & 214267 & $\leq 0.11$ & JCMT \\
\hline & $13_{0,13}-12_{1,12} \ldots$ & 213857 & 0.085 : & $\mathrm{JCMT}^{\mathbf{b}}$ \\
\hline & $12_{2,12}-12_{1,11} \ldots \ldots$ & 262154 & $\leq 0.09$ & JCMT \\
\hline & $15_{0,15}^{2,14_{1,14}} \ldots \ldots$ & 247913 & $\leq 0.22$ & JCMT \\
\hline & $6_{5,2}-5_{4,1} \ldots \ldots \ldots \ldots$ & 340188 & 0.15 : & $\mathrm{CSO}$ \\
\hline \multirow[t]{2}{*}{$\mathrm{CH}_{3} \mathrm{OCH}_{3}$} & $5_{3,3}-4_{2,2} \ldots \ldots \ldots \ldots$ & 240985 & $\leq 0.11$ & JCMT \\
\hline & $13_{1,13}-12_{0,12} \ldots \ldots$ & 241946 & $\leq 0.10$ & JCMT \\
\hline \multirow[t]{2}{*}{$\mathrm{C}_{2} \mathrm{H}_{3} \mathrm{CN}$} & $26_{0,26}-25_{0,25} \ldots \ldots$ & 239708 & $\leq 0.18$ & JCMT \\
\hline & $26_{2,25}-25_{2,24} \cdots \ldots$ & 244857 & $\leq 0.13$ & JCMT \\
\hline \multirow{4}{*}{$\begin{array}{l}\mathrm{C}_{2} \mathrm{H}_{5} \mathrm{CN} \\
\mathrm{CH}_{2} \mathrm{NH} \\
\mathrm{NH}_{2} \mathrm{CHO}\end{array}$} & $9_{45}-8,3 \ldots \ldots \ldots$ & 242788 & $\leq 0.11$ & JCMT \\
\hline & $4_{14}-3_{13} \ldots \ldots \ldots \ldots$ & 245126 & $\leq 0.18$ & JCMT \\
\hline & $10_{2,9}-9_{2,8} \ldots \ldots \ldots$ & 211329 & $\leq 0.11$ & JCMT \\
\hline & $16_{1,15}-15_{2,14} \ldots \ldots$ & 242074 & $\leq 0.13$ & JCMT \\
\hline \multirow[t]{4}{*}{$\mathrm{NH}_{2} \mathrm{CN}$} & $11_{1,11}-10_{1,10} \cdots$ & $218395 / 462$ & $\leq 0.09$ & JCMT \\
\hline & $12_{0,12}-11_{0,11} \ldots \ldots$ & 239683 & $\leq 0.18$ & JCMT \\
\hline & $12_{0,12}-11_{0,11} \ldots \ldots$ & 239872 & $\leq 0.11$ & JCMT \\
\hline & $12_{1,11}-11_{1,10} \ldots$. & 241479 & $\leq 0.07$ & $\mathrm{JCMT}$ \\
\hline
\end{tabular}

NoTE.-All limits are $2 \sigma$ in a $1 \mathrm{MHz}$ bandwidth.

an wing of $\mathrm{CH}_{3} \mathrm{OH}$.

${ }^{b}$ Blend with $\mathrm{NH}_{2} \mathrm{D}_{22}-3_{12}$. included in Table 9. If this gas is assumed to have the same characteristics as the gas seen in absorption at the IRAS source position, the two analyses are consistent for the lower temperature and density, $T_{\text {kin }} \approx 15 \mathrm{~K}$ and $n\left(\mathrm{H}_{2}\right) \approx 3 \times 10^{4} \mathrm{~cm}^{-3}$. As noted above, a proper chemical study of the ambient cloud would require observations at lower frequencies, $\sim 30-100$ $\mathrm{GHz}$.

In summary, the molecular lines observed in this work appear to trace at least three of the components of the IRAS 16293-2422 environment. Organics such as $\mathrm{CH}_{3} \mathrm{OH}$, $\mathrm{CH}_{3} \mathrm{CN}, \mathrm{HC}_{3} \mathrm{~N}$, and at least part of the $\mathrm{H}_{2} \mathrm{CO}$ probe the interaction of the outflow with the warm, inner part of the circumbinary envelope. The circumbinary envelope itself is seen in common species such as $\mathrm{CS}, \mathrm{HCO}^{+}$, and $\mathrm{H}_{2} \mathrm{CO}$. In contrast, radicals such as $\mathrm{CN}, \mathrm{C}_{2} \mathrm{H}$, and $\mathrm{C}_{3} \mathrm{H}_{2}$ trace mostly the colder, less dense outer part of the envelope. The coldest, lowest density gas of the ambient cloud is seen as selfabsorption in lines of common molecules such as $\mathrm{CS}, \mathrm{HCO}^{+}$, and $\mathrm{HCN}$. Only the emission from the true circumstellar disks (component 1 ) is too diluted in our $20^{\prime \prime}$ beam to be unambiguously detected.

The physical and chemical differentiation found for IRAS $16293-2422$ is similar to that observed for the low-mass object NGC 1333 IRAS 4 (Blake et al. 1995). Because the outflow axis is oriented more along the line of sight in the latter case, the various physical components can be better distinguished kinematically in NGC 1333 IRAS 4. Molecules such as $\mathrm{CH}_{3} \mathrm{OH}, \mathrm{H}_{2} \mathrm{CO}$, and $\mathrm{HCN}$, as well as $\mathrm{SiO}$ and $\mathrm{SO}$, exhibit strong emission in the "wing" component associated with the outflow, just as in the case of IRAS $16293-2422$. SiO is even kinematically displaced from the other species, indicating a more direct shock origin for that molecule. On the other hand, species such as $\mathrm{HCO}^{+}$show mostly narrow lines associated with the quiescent "core" gas. The main difference between the two sources lies in the excitation temperature of the molecules in the outflow component: in NGC 1333 IRAS 4, the rotational temperatures are low, $T_{\mathrm{ROT}} \approx 20 \mathrm{~K}$ for e.g., $\mathrm{CH}_{3} \mathrm{OH}$, whereas in IRAS $16293-2422$ they are high. This may be due to the fact that IRAS $16293-2422$ is somewhat further evolved than NGC 1333 IRAS 4, or to subthermal excitation in the latter case.

TABLE 8

ANALYSIS OF SELF-ABSORBED LINES

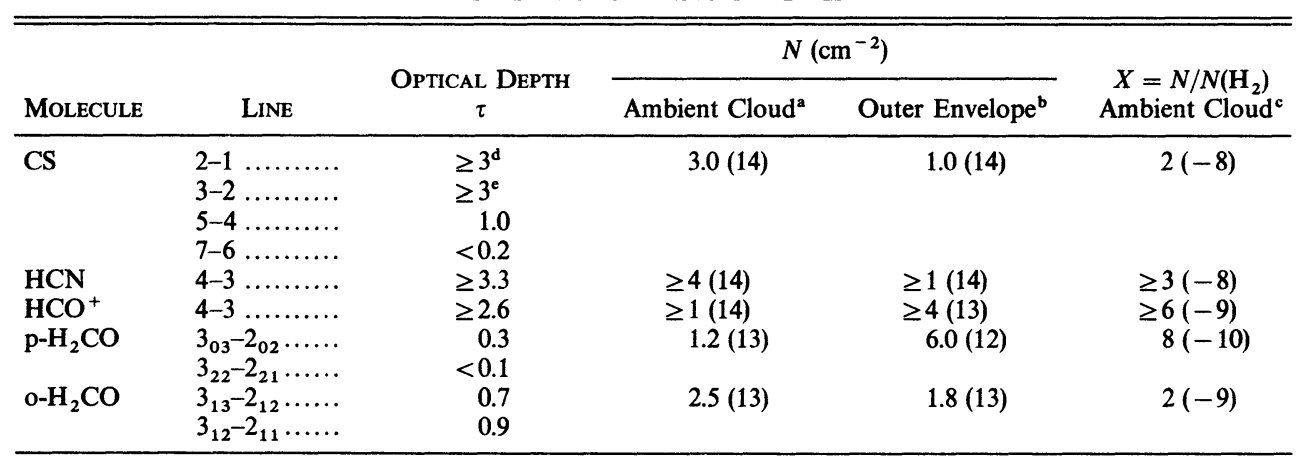

a Assuming $T=15 \mathrm{~K}, n\left(\mathrm{H}_{2}\right)=3 \times 10^{4} \mathrm{~cm}^{-3}, \Delta V=1.5 \mathrm{~km} \mathrm{~s}^{-1}$.

${ }^{b}$ Assuming $T=20 \mathrm{~K}, n\left(\mathrm{H}_{2}\right)=2 \times 10^{5} \mathrm{~cm}^{-3}, \Delta V=1.5 \mathrm{~km} \mathrm{~s}^{-1}$.

c Assuming $N\left(\mathrm{H}_{2}\right)=1.5 \times 10^{22} \mathrm{~cm}^{-2}$ derived from $\mathrm{C}^{18} \mathrm{O}$ observations at $120^{\prime \prime}$ south position.

d From Walker et al. 1986.

e From Menten et al. 1987. 
TABLE 9

Observed lines and Derived Column Densities at 120" South Position

\begin{tabular}{|c|c|c|c|c|c|c|c|}
\hline \multirow[b]{2}{*}{ Molecule } & \multirow[b]{2}{*}{ LiNE } & \multirow[b]{2}{*}{$\int T_{\mathrm{MB}} d V$} & \multirow[b]{2}{*}{$T_{\mathrm{MB}}$} & \multirow[b]{2}{*}{$\Delta V$} & \multicolumn{2}{|c|}{$N\left(\mathrm{~cm}^{-2}\right)$} & \multirow{2}{*}{$\begin{array}{c}X=N / N\left(\mathrm{H}_{2}\right) \\
\text { Ambient Cloud }^{c}\end{array}$} \\
\hline & & & & & Ambient Cloud $^{\mathrm{a}}$ & Outer Envelope $^{b}$ & \\
\hline${ }^{12} \mathrm{CO}$ & $2-1 \ldots \ldots \ldots \ldots \ldots$ & 18.9 & 11.1 & 1.61 & $1.5(18)^{d}$ & $1.4(18)^{d}$ & $1(-4)^{d}$ \\
\hline $\mathrm{C}^{18} \mathrm{O}$ & $2-1 \ldots \ldots \ldots \ldots \ldots \ldots$ & 4.5 & 2.9 & 1.44 & 3.0 (15) & $2.7(15)$ & $2(-7)$ \\
\hline $\mathrm{CS}$ & $5-4 \ldots \ldots \ldots \ldots \ldots$ & $\ldots$ & $<0.36$ & $\ldots$ & $<3(14)$ & $<3(13)$ & $<2(-8)$ \\
\hline $\mathrm{p}-\mathrm{H}_{2} \mathrm{CO}$ & $3_{03}-2_{02} \ldots \ldots \ldots \ldots$ & $\ldots$ & $<0.36$ & $\ldots$ & $<5(13)$ & $<5(12)$ & $<3(-9)$ \\
\hline $\mathrm{O}-\mathrm{H}_{2} \mathrm{CO}$ & $3_{13}-2_{12} \ldots \ldots \ldots \ldots$ & $\ldots$ & $<0.36$ & $\ldots$ & $<4$ (13) & $<5(12)$ & $<3(-9)$ \\
\hline $\mathrm{CN}^{2}$ & $2, \frac{5}{2}-1, \frac{3}{2} \ldots \ldots \ldots$ & $\ldots$ & $<0.27$ & $\ldots$ & $<2(14)$ & $<2(13)$ & $<1(-8)$ \\
\hline $\mathrm{C}_{3} \mathrm{H}_{2}$ & $4_{32}-3_{21} \ldots \ldots \ldots \ldots$ & $\ldots$ & $<0.1$ & $\ldots$ & <1(14) & $<1$ (13) & $<1(-8)$ \\
\hline SO & $\begin{array}{l}5_{5}-4_{4} \ldots \ldots \ldots \ldots \ldots \\
6_{6}-5_{5} \ldots \ldots \ldots \ldots \ldots \ldots\end{array}$ & $\begin{array}{l}\ldots \\
\ldots\end{array}$ & $\begin{array}{l}<0.22 \\
<0.36\end{array}$ & $\ldots$ & $<2(15)$ & $<1(14)$ & $<1(-7)$ \\
\hline $\mathrm{SO}_{2}$ & $11_{1,11}-10_{0,10} \ldots \ldots$ & $\cdots$ & $<0.15$ & $\cdots$ & $<3(14)$ & $<2(14)$ & $<2(-8)$ \\
\hline
\end{tabular}

${ }^{a}$ Using $T=15 \mathrm{~K}, n\left(\mathrm{H}_{2}\right)=3 \times 10^{4} \mathrm{~cm}^{-3}$.

${ }^{b}$ Using $T=20 \mathrm{~K}, n\left(\mathrm{H}_{2}\right)=2 \times 10^{5} \mathrm{~cm}^{-3}$.

${ }^{c}$ Using $N\left(\mathrm{H}_{2}\right)=1.5 \times 10^{22} \mathrm{~cm}^{-2}$ derived from $\mathrm{C}^{18} \mathrm{O}$ assuming isotopic ratios.

${ }^{d}$ From $\mathrm{C}^{18} \mathrm{O}$ assuming normal isotopic ratios.

\subsection{Beam-averaged Abundances}

\subsubsection{Organic Molecules}

Table 10 summarizes the column densities of the various species averaged over a $20^{\prime \prime}$ beam. Results of both the rotation diagram method and of the statistical equilibrium calculations, wherever available, are included. The column densities derived by the latter method are to be preferred.

In analogy with Paper I, Table 10 also presents the relative abundances in IRAS $16293-2422$ using $N\left(\mathrm{H}_{2}\right)=2 \times 10^{23}$ $\mathrm{cm}^{-2}$ in a $20^{\prime \prime}$ beam, as derived from $\mathrm{C}^{17} \mathrm{O}$ observations. For comparison, the abundances found in the dark cloud L134N and in the Orion hot core and compact ridge are included in the table. It is seen that radicals such as $\mathrm{C}_{3} \mathrm{H}_{2}, \mathrm{CN}$, and $\mathrm{C}_{2} \mathrm{H}$ are clearly less abundant in IRAS 16293-2422 compared with cold dark clouds like L134N and TMC-1 (see Ohishi, Irvine, \& Kaifu 1992 for a summary of the TMC-1 abundances). Even the beam-averaged abundances of $\mathrm{HCN}, \mathrm{HCO}^{+}$, and $\mathrm{H}_{2} \mathrm{CO}$ appear to be lower than those found in the ambient cloud (see Tables 8 and 9).

Compared with high-mass star-forming regions such as the Orion hot core or compact ridge, the abundances of complex saturated organic molecules like $\mathrm{CH}_{3} \mathrm{OH}, \mathrm{CH}_{3} \mathrm{CHO}$, and $\mathrm{CH}_{3} \mathrm{OCH}_{3}$ are also lower. However, the relative abundances of the organic species, such as $\mathrm{CH}_{3} \mathrm{OH} / \mathrm{C}_{2} \mathrm{H}_{5} \mathrm{OH} \geq 22$ and $\mathrm{CH}_{3} \mathrm{OH} / \mathrm{CH}_{3} \mathrm{OCH}_{3} \geq 3$, are consistent with those found in the Orion hot core or compact ridge (Blake et al. 1987). Ketene $\left(\mathrm{CH}_{2} \mathrm{CO}\right)$ may actually be somewhat more abundant relative to $\mathrm{CH}_{3} \mathrm{OH}$ in IRAS $16293-2422$ than in Orion. On the other hand, all ratios are at least an order of magnitude lower than those found in the richest source of organic molecules, Sgr B2 (Turner 1991; Sutton et al. 1991). The relative overabundance of $\mathrm{CH}_{2} \mathrm{CO}$ could be due to the somewhat longer timescale since evaporation in IRAS 16293-2422 compared with Orion, since this molecule appears to peak at a somewhat later time as it is formed by slower neutral-neutral reactions (Charnley et al. 1992).

It should be emphasized that the beam-averaged abundances listed in Table 10 have only limited meaning since the various molecules sample different physical regimes with different sizes, as discussed in $\S 5.1$. A more sophisticated analysis should take gradients in chemical abundances in the different regions into account. For example, molecules which are present mostly in the small outflow interaction region are likely to have abundances that are higher by about a factor of 100 due to the large beam dilution of these species relative to CO (see Paper I). The values for these species would then approach those found in Orion and in the NGC 1333 IRAS 4 "wing" component. Similarly, those molecules located mainly in the inner part of the circumbinary envelope may be more abundant by a factor of 10 . On the other hand, the tabulated abundances of radicals such as $\mathrm{CN}$ and $\mathrm{C}_{3} \mathrm{H}_{2}$ will be representative of the outer part of the envelope; these species will probably have lower abundances in the inner part. A more quantitative analysis will be presented in a subsequent paper.

The $\mathrm{HCN} / \mathrm{HNC}$ ratio is often used as another indicator of the physical state of an object (e.g., Schilke et al. 1992). The observed ratio in IRAS 16293-2422 averaged over our 20" beam is $\sim 12$, substantially lower than the value of $\sim 80$ found in the Orion plateau by Schilke et al. Again, this ratio may vary from component to component and may well be higher in the outflow component, but lower in the outer part of the envelope.

\subsubsection{Deuterated Species}

The relative abundances of the deuterated molecules with respect to their main isotopic counterparts are summarized in Table 11, where they are compared with the observed deuterium fractionation ratios in TMC-1 and the Orion hot core. As indicated in Table 10, the observed column densities of the deuterated molecules have typical uncertainties of factors of 1.5-2, where the largest uncertainty stems from poor constraints on the physical parameters of the gas where the molecules reside. The column densities of the main isotopic species are generally better determined. Wherever possible, the column densities derived from the statistical equilibrium calculations are used. The IRAS $16293-2422$ ratios therefore have typical uncertainties of $\sim 50 \%$, but it is clear that they are very large. For molecules such as $\mathrm{HDCO}$ and $\mathrm{NH}_{2} \mathrm{D}$ the observed ratios are closer to those found in hot cores than in cold clouds. Even for species not expected to be present in hot cores, such as $\mathrm{DCO}^{+}$and $\mathrm{CCD}$, the observed values are higher than those found in TMC-1. The large $\mathrm{HDO} / \mathrm{H}_{2} \mathrm{O}$ abundance ratio has been derived using $N\left(\mathrm{H}_{2} \mathrm{O}\right)<10^{17} \mathrm{~cm}^{-2}$ inferred from the $\mathrm{H}_{3} \mathrm{O}^{+}$upper limit (see $\S 4.7$ ) and corresponds to a $\mathrm{H}_{2} \mathrm{O}$ abundance of less than $5 \times 10^{-7}$. The presence of $\mathrm{H}_{2} \mathrm{O}$ maser emis- 
TABLE 10

Molecular Column Densities and Abundances Averaged over 20" Beam

\begin{tabular}{|c|c|c|c|c|c|c|}
\hline \multirow[b]{2}{*}{ SPECIES } & \multicolumn{2}{|c|}{$N\left(\mathrm{~cm}^{-2}\right)$} & \multicolumn{4}{|c|}{$X=N / N\left(\mathbf{H}_{2}\right)$} \\
\hline & Rot. Diagrama & Exc. Calculation & IRAS $16293^{b}$ & $\mathrm{~L} 134 \mathrm{~N}^{\mathrm{c}}$ & Orion Hot Core $^{d}$ & Compact Ridge \\
\hline $\mathrm{HCO}^{+} .$. & $\cdots$ & & $1.8(-9)^{e}$ & $8(-9)$ & $<1(-9)$ & $\ldots$ \\
\hline $\mathbf{H}^{13} \mathrm{CO}^{+} \ldots \ldots \ldots$ & $\ldots$ & $1.5(12)$ & $7.5(-12)$ & $\ldots$ & $\ldots$ & $\ldots$ \\
\hline $\mathrm{HC}^{18} \mathrm{O}^{+} \ldots \ldots \ldots$ & $\ldots$ & $7.0(11)$ & $3.5(-12)$ & & $\ldots$ & $\ldots$ \\
\hline HCN $\ldots \ldots \ldots \ldots$ & $\ldots$ & $\ldots$ & $1.9(-9)^{e^{e}}$ & $4(-9)$ & $2(-7)$ & $\ldots$ \\
\hline $\mathrm{H}^{13} \mathrm{CN} \ldots \ldots \ldots \ldots$ & $\ldots$ & $2.8(12)$ & $1.4(-11)$ & $\ldots$ & $\ldots$ & $\ldots$ \\
\hline $\mathrm{HC}^{15} \mathrm{~N} \ldots \ldots \ldots$ & $\ldots$ & $1.4(12)$ & $7.0(-12)$ & & $\ldots$ & $\ldots$ \\
\hline HNC ........... & $\ldots$ & $\ldots$ & $1.5(-10)^{e}$ & $6(-9)$ & $\ldots$ & $\ldots$ \\
\hline $\mathrm{HN}^{13} \mathrm{C} \ldots \ldots \ldots$ & $\ldots$ & $5.0(11)$ & $2.5(-12)$ & & $\ldots$ & $\ldots$ \\
\hline $\mathrm{CN}, \ldots \ldots \ldots \ldots$ & $(3.7 \pm 2.0)(13)$ & $2.0(13)$ & $1.0(-10)$ & $<3(-9)$ & $\ldots$ & $\ldots$ \\
\hline $\mathrm{C}_{2} \mathrm{H} \ldots \ldots \ldots \ldots$ & $(9.2 \pm 5.9)(13)$ & $5.0(13)$ & $2.5(-10)$ & $<5(-8)$ & $\ldots$ & $\ldots$ \\
\hline $\mathrm{C}_{3} \mathrm{H}_{2} \ldots \ldots \ldots \ldots$ & $(8.6 \pm 3.0)(11)$ & $7.0(12)$ & $3.5(-11)$ & $2(-9)$ & $<4(-10)$ & \\
\hline $\mathrm{H}_{2} \mathrm{CO} \ldots \ldots \ldots \ldots$ & $(2.1 \pm 0.3)(14)$ & $1.4(14)$ & $7.0(-10)$ & $2(-8)$ & $>6(-8)$ & $2(-8)$ \\
\hline $\mathrm{CH}_{3} \mathrm{OH} \ldots \ldots \ldots$ & $(8.8 \pm 1.0)(14)$ & $\ldots$ & $4.4(-9)$ & $3(-9)$ & $(0.1-1)(-6)$ & $1(-7)$ \\
\hline $\mathrm{CH}_{3} \mathrm{CN} \ldots \ldots \ldots$ & $(3.0 \pm 2.0)(13)$ & $\ldots$ & $1.5(-10)$ & $<4(-10)$ & $5(-9)$ & $3(-10)$ \\
\hline $\mathrm{CH}_{3} \mathrm{C}_{2} \mathrm{H} \ldots \ldots \ldots$ & $(1.3 \pm 1.0)(14)$ & $\ldots$ & $6.5(-10)$ & $<1(-9)$ & $\ldots$ & $\ldots$ \\
\hline $\mathrm{HC}_{3} \mathrm{~N} \ldots \ldots \ldots \ldots$ & $(3.5 \pm 1.5)(12)$ & $5.0(12)$ & $2.5(-11)$ & $2(-10)$ & $1(-9)$ & $\ldots$ \\
\hline HNCO ........... & $(3.4 \pm 1.5)(13)$ & $\ldots$ & $1.7(-10)$ & $\ldots$ & $5(-9)$ & $\ldots$ \\
\hline $\mathrm{CH}_{2} \mathrm{CO} \ldots \ldots \ldots$ & $3.6(13):$ & $\ldots$ & $1.8(-10):$ & $<7(-10)$ & $\ldots$ & $7(-10)$ \\
\hline $\mathrm{DCO}^{+} \ldots \ldots \ldots \ldots$ & $(4.8 \pm 2.0)(12)$ & $3.0(12)$ & $1.5(-11)$ & $\ldots$ & $\ldots$ & $\ldots$ \\
\hline DCN $\ldots \ldots \ldots \ldots$ & $(4.6 \pm 2.0)(12)$ & $5.0(12)$ & $2.5(-11)$ & $\ldots$ & $6(-10)$ & $\ldots$ \\
\hline DNC $\ldots \ldots \ldots \ldots$ & $(2.5 \pm 2.0)(12)$ & $1.0(12)$ & $5.0(-12)$ & $\ldots$ & $\ldots$ & $\ldots$ \\
\hline CCD $\ldots \ldots \ldots \ldots$ & $\ldots$ & $9.0(12)$ & $4.5(-11)$ & $\ldots$ & $\ldots$ & $\ldots$ \\
\hline HDO ............ & $\ldots$ & $2.0(15)$ & $1.0(-8)$ & $\ldots$ & $4(-8)$ & $\ldots$ \\
\hline HDCO ........... & $(2.2 \pm 2)(13)$ & $\ldots$ & $1.1(-10)$ & $\ldots$ & $\ldots$ & $\ldots$ \\
\hline $\mathrm{NH}_{2} \mathrm{D} \ldots \ldots \ldots \ldots$ & $(1.9 \pm 0.7)(14)$ & $\ldots$ & $1.0(-9)$ & $\ldots$ & $\ldots$ & $\ldots$ \\
\hline HDS $\ldots \ldots \ldots \ldots$ & $(3.0 \pm 1.5)(13)$ & $\ldots$ & $1.5(-10)$ & $\ldots$ & $\ldots$ & $\ldots$ \\
\hline NO $\ldots \ldots \ldots \ldots$ & $<1(19)$ & $\ldots$ & $<5(-5)$ & $6(-8)$ & $\ldots$ & $\ldots$ \\
\hline $\mathrm{C}_{3} \mathrm{O} \ldots \ldots \ldots \ldots$ & $<2(14)$ & $\ldots$ & $<1(-9)$ & $<5(-11)$ & $\ldots$ & $\ldots$ \\
\hline$C_{3} S \ldots \ldots \ldots \ldots \ldots$ & $<1(15)$ & $\ldots$ & $<5(-9)$ & $<2(-10)$ & $\ldots$ & $\ldots$ \\
\hline $\mathrm{H}_{3} \mathbf{O}^{+} \ldots \ldots \ldots \ldots$ & & $<1(13)$ & $<5(-11)$ & $\ldots$ & $1(-9)$ & $\ldots$ \\
\hline HCO $\ldots \ldots \ldots \ldots$ & $<4(13)$ & $\ldots$ & $<2(-10)$ & $\ldots$ & $\ldots$ & $\ldots$ \\
\hline НСООН......... & $<6(13)$ & $\ldots$ & $<3(-10)$ & $3(-10)$ & $\ldots$ & $5(-10)$ \\
\hline $\mathrm{CH}_{3} \mathrm{CHO} \ldots \ldots \ldots$ & $<2(13)$ & $\ldots$ & $<1(-10)$ & $6(-10)$ & $\ldots$ & $\leq 2(-10)$ \\
\hline $\mathrm{C}_{2} \mathrm{H}_{5} \mathrm{OH} \ldots \ldots \ldots$ & $\$ 4(13)$ & $\ldots$ & $\lesssim 2(-10)^{f}$ & $\ldots$ & $\ldots$ & $<5(-10)$ \\
\hline $\mathrm{CH}_{3} \mathrm{OCH}_{3} \ldots \ldots$ & $<3(14)$ & $\ldots$ & $<2(-9)$ & $\ldots$ & $\ldots$ & $1(-8)$ \\
\hline $\mathrm{C}_{2} \mathrm{H}_{3} \mathrm{CN} \ldots \ldots \ldots$ & $<1(15)$ & $\ldots$ & $<5(-9)$ & $\ldots$ & $2(-9)$ & $\ldots$ \\
\hline $\mathrm{C}_{2} \mathrm{H}_{5} \mathrm{CN} \ldots \ldots \ldots$ & $<2(14)$ & $\ldots$ & $<1(-9)$ & $\ldots$ & $8(-9)$ & $\ldots$ \\
\hline $\mathrm{CH}_{2} \mathrm{NH} \ldots \ldots \ldots$ & $<1(14)$ & $\ldots$ & $<5(-10)$ & $\ldots$ & $\ldots$ & $\ldots$ \\
\hline $\mathrm{NH}_{2} \mathrm{CHO} \ldots \ldots$ & $<8(12)$ & $\ldots$ & $<4(-11)$ & $\ldots$ & $\ldots$ & $<1(-10)$ \\
\hline $\mathrm{NH}_{2} \mathrm{CN} \ldots \ldots \ldots$ & $<2(12)$ & $\ldots$ & $<1(-11)$ & $\ldots$ & $\ldots$ & $<1(-10)$ \\
\hline
\end{tabular}

All upper limits assume $T_{\mathrm{ex}}=20-80 \mathrm{~K}$ and $\Delta V=3 \mathrm{~km} \mathrm{~s}^{-1}$, unless otherwise indicated.

' Using $N\left(\mathrm{H}_{2}\right)=2 \times 10^{23} \mathrm{~cm}^{-2}$ in a $20^{\prime \prime}$ beam as derived from $\mathrm{C}^{17} \mathrm{O}$.

c From Ohishi et al. 1992.

d From Blake et al. 1987.

- Derived from isotopic column densities assuming normal isotope ratios.

f Assuming $T_{\text {ex }}=85 \mathrm{~K}$, similar to $\mathrm{CH}_{3} \mathrm{OH}$.

sion indicates that locally the $\mathrm{H}_{2} \mathrm{O}$ abundance may be substantially higher, which would bring the $\mathrm{HDO} / \mathrm{H}_{2} \mathrm{O}$ ratio closer to that observed for other hot cores by Jacq et al. (1990).

The large amount of deuterated molecules is one of the most remarkable aspects of IRAS 16293-2422 compared with other regions. One possible explanation could be that, e.g., DCN and HDCO are more broadly distributed than $\mathrm{HCN}$ and $\mathrm{H}_{2} \mathrm{CO}$ in the 20" beam: $\mathrm{HCN}$ and $\mathrm{H}_{2} \mathrm{CO}$ are present mostly in the inner part, whereas the deuterated species have substantial abundances also in the cold outer envelope. However, even if the beam dilution of the main isotopic species is taken to be a factor of $\sim 4$ compared with the deuterated molecules (cf. the source sizes derived in $\S 4.1$ and 4.2), the ratios are still substantial. The observed ratios thus suggest a scenario similar to that of OMC-1 and other hot cores, where highly deuterated molecules, formed in cold prestellar cores and on grains during the collapse, have only recently been released from the grains. The lower mass of IRAS 16293-2422 compared to the other hot cores may actually enhance this effect, since it ensures longer evolutionary times and hence longer times at the high densities and low temperatures which drive fractionation toward extreme values such as those observed.

If grain surface chemistry is indeed significant for some of the deuterated species and organics, it provides a clue to the mechanism by which these molecules are removed from the grains: in contrast with the high-mass star-forming regions, the luminosity of IRAS $16293-2422$ is too low to radiatively heat the majority of the grains (Mundy et al. 1992). Thus, removal by, e.g., grain-grain collisions in the shocked zones is a 
TABLE 11

ObSERVED DeUterium Fractionation Ratios in 20" BeAM $^{\text {a }}$

\begin{tabular}{|c|c|c|c|}
\hline Molecule & IRAS $16293-2422^{b}$ & TMC-1 & Hot Cores \\
\hline $\mathrm{DCO}^{+} / \mathrm{HCO}^{+}$ & 0.0086 & 0.015 & \\
\hline $\mathrm{DCN} / \mathrm{HCN} \ldots$ & 0.013 & 0.023 & $0.005-0.02^{\mathrm{c}}$ \\
\hline DNC/HNC ........... & 0.03 & 0.015 & $\ldots$ \\
\hline $\mathrm{C}_{2} \mathrm{D} / \mathrm{C}_{2} \mathrm{H} \ldots \ldots \ldots \ldots \ldots$ & 0.18 & 0.01 & \\
\hline $\mathrm{HDCO} / \mathrm{H}_{2} \mathrm{CO} \ldots \ldots \ldots$ & 0.14 & 0.015 & $0.14^{d}$ \\
\hline $\mathrm{NH}_{2} \mathrm{D} / \mathrm{NH}_{3} \ldots \ldots \ldots \ldots$ & $0.1:^{\mathrm{e}}$ & $<0.02$ & $0.06^{\mathrm{f}}$ \\
\hline $\mathrm{HDO} / \mathrm{H}_{2} \mathrm{O} \ldots \ldots \ldots \ldots$ & $\gtrsim 0.01^{\mathrm{g}}$ & $\ldots$ & $0.001-0.004^{\mathrm{h}}$ \\
\hline $\mathrm{CH}_{3} \mathrm{OD} / \mathrm{CH}_{3} \mathrm{OH} \ldots \ldots$ & $\leq 0.1$ & $\ldots$ & $0.01-0.06^{i}$ \\
\hline $\mathrm{HDS} / \mathrm{H}_{2} \mathrm{~S} \ldots \ldots \ldots \ldots \ldots$ & 0.10 & $\ldots$ & $\ldots$ \\
\hline
\end{tabular}

a Adapted from Millar, Bennett, \& Herbst 1989; Irvine \& Knacke 1989; and van Dishoeck et al. 1993a.

b Observed ratios in IRAS $16293-2422$ have a typical uncertainty of $50 \%$.

c Mangum et al. 1991.

d Turner 1990.

e Using $\mathrm{NH}_{3}$ column density derived by Mundy et al. 1990.

f Reassessment of Turner 1990 of data of Walmsley et al. 1987.

${ }^{g}$ Using $N\left(\mathrm{H}_{2} \mathrm{O}\right)<10^{17} \mathrm{~cm}^{-2}$ as derived from the $\mathrm{H}_{3} \mathrm{O}^{+}$upper limit.

h Jacq et al. 1990.

i Mauersberger et al. 1988.

more likely explanation. Further observations of many starforming cores as functions of both luminosity and age will be required to clarify these critical issues.

\section{CONCLUSIONS}

Submillimeter line surveys in the 230 and $345 \mathrm{GHz}$ windows have revealed that IRAS $16293-2422$ is a rich source of molecular lines. The analysis of the data presented in this work confirms that several different physical regimes occur on a $20^{\prime \prime}$, or $3000 \mathrm{AU}$, scale. Organic molecules such as $\mathrm{CH}_{3} \mathrm{OH}$, $\mathrm{CH}_{3} \mathrm{CN}$, and part of the $\mathrm{H}_{2} \mathrm{CO}$ appear to trace the warm $\left(T_{\text {kin }} \approx 80 \mathrm{~K}\right.$ or higher) and dense $\left[n\left(\mathrm{H}_{2}\right) \approx(0.5-1) \times 10^{7}\right.$ $\mathrm{cm}^{-3}$ ] interaction region of the outflow(s) with the circumbinary envelope. Part of the emission from these molecules, as well as that of species such as $\mathrm{HCO}^{+}$and $\mathrm{CS}$, also arises from the more quiescent circumbinary envelope with $T_{\text {kin }} \approx 40 \mathrm{~K}$ and $n\left(\mathrm{H}_{2}\right) \approx 10^{6}-10^{7} \mathrm{~cm}^{-3}$. Radicals such as $\mathrm{CN}, \mathrm{C}_{2} \mathrm{H}$, and $\mathrm{C}_{3} \mathrm{H}_{2}$ are present mostly in the outer, less dense region of the envelope. Very high deuterium fractionation ratios are found, reminiscent of those found in hot core regions. Large chemical gradients are likely to occur between the various physical regimes. As a result, the beam-averaged abundances summarized in Table 10 only have a limited meaning.

Generally speaking, these chemical modifications are to be expected during the star formation process. The rapidly increasing density and centrally concentrated nature of the outwardly propagating collapse phase should lead to situations in which the outlying regions of star-forming cores appear much the same as ambient molecular cloud material, but in which the interior has a distinct chemical composition. In particular, once outflows are initiated by the young (still accreting) stars, new chemical channels are opened and the composition is altered by destruction of the refractory grain cores and removal of accreted grain mantles. As emphasized in this paper, it is much more difficult to discern the quantitative nature of these changes and therefore the relative importance of the evolutionary stage of the object compared with its mass and luminosity. As a whole, the physical and chemical characteristics of IRAS 16293-2422 resemble at last qualitatively those found in high-mass star-forming regions such as Orion$\mathrm{KL}$. The next step in this study is obviously to build a consistent, multicomponent physical model and derive abundances for each of the components separately. The extensive data sets presented in Paper I and this paper provide an unique opportunity to perform such detailed modeling for the first time for a low-mass YSO.

E. F. v. D. and D. J. J. are grateful to the Netherlands Organization for Scientific Research (NWO) for support through a PIONIER grant. G. A. B. acknowledges support from the NASA Origins of Solar Systems and Exobiology programs as well as the David and Lucile Packard and Alfred P. Sloan Foundations.

\section{REFERENCES}

Bachiller, $R$, Martín-Pintado, J, \& Fuente, A 1991, A\&A, 243, L21

Blake, G. A., Sutton, E. C., Masson, C. R., \& Phillips, T. G. 1987, ApJ, 315, 621

Blake, G. A., van Dishoeck, E. F., Jansen, D. J., Groesbeck, T. D., \& Mundy, L. G. 1994, ApJ, 428, 680 (Paper I)

Blake, G. A., Sandell, G., van Dishoeck, E. F., Groesbeck, T. D., Mundy, L. G., \& Aspin, C. 1995, ApJ, 441, 689

Brown, P. D., Charnley, S. B., \& Millar, T. J. 1988, MNRAS, 231, 409

Brown, P. D., \& Millar, T. J. 1989, MNRAS, 237, 661

Caselli, P., Hasegawa, T. I., \& Herbst, E. 1993, ApJ, 408, 548

Charnley, S. B., Tielens, A. G. G. M., \& Millar, T. J. 1992, ApJ, 399, L71

Churchwell, E., Wood, D., Myers, P. C., \& Myers, R. V. 1986, ApJ, 305, 405

Evans, N. J. 1980, in IAU Symp. 87, Interstellar Molecules, ed. B. H. Andrew (Dordrecht: Reidel), 1

Genzel, R. 1992, in The Galactic Interstellar Medium, ed. W. B. Burton, B. G. Elmegreen, \& R. Genzel (Berlin: Springer), 275

Goldsmith, P. F. 1984, in Galactic and Extragalactic Infrared Spectroscopy, ed. M. F. Kessier \& J. P. Phillips (Dordrecht: Reidel), 233

Groesbeck, T. D. 1994, Ph.D. thesis, Caltech

Hartquist, T. W., Nejad, L. A. M., \& Williams, D. A. 1993a, in Dust and Chemistry, ed. T. J. Millar \& D. A. Williams (Dordrecht: Kluwer), 205

Hartquist, T. W., Rawlings, J. M. C., Williams, D. A., \& Dalgarno, A. 1993b, QJRAS, 34, 213

Helmich, F. P., Jansen, D. J., de Graauw, T., Groesbeck, T., \& van Dishoeck, E. F. 1994, A\&A, 283, 626

Irvine, W. M., Goldsmith, P. F., \& Hjalmarson, A. 1987, in Interstellar Processes, ed. D. Hollenbach \& H. A. Thronson (Dordrecht: Reidel), 561

Irvine, W. M., \& Knacke, R. F. 1989, in Origin and Evolution of Planetary and Satellite Atmospheres, ed. S. K. Atreya, J. B. Pollack, \& M. S. Matthews (Tucson: Univ. Arizona Press), 386
Jacq, T., Walmsley, C. M., Henkel, C., Baudry, A., Mauersberger, R., \& Jewell, P. R. 1990, A\&A, 228, 447

Jansen, D. J., van Dishoeck, E. F., \& Black, J. H. 1994, A\&A, 282, 605

Mangum, J., Plambeck, R. L., \& Wootten, A. 1991, ApJ, 369, 169

Mangum, J., \& Wootten, A. 1993, ApJS, 89, 123

Martín-Pintado, J., Bachiller, R., \& Fuente, A. 1992, A\&A, 254, 315

Mauersberger, R., Henkel, C., Jacq, T., \& Walmsley, C. M. 1988, A\&A, 194, L1

Menten, K. M., Serabyn, E., Güsten, R., \& Wilson, T. L. 1987, A\&A, 177, L57

Mezger, P. G., Sievers, A., Zylka, R., Haslam, C. G. T., Kreysa, E., \& Lemke, R. 1992, A\&A, 265, 743

Millar, T. J. 1993, in Dust and Chemistry, ed. T. J. Millar \& D. A. Williams (Dordrecht: Kluwer), 249

Millar, T. J., Bennett, A., \& Herbst, E. 1989, ApJ, 340, 906

Millar, T. J., Herbst, E., \& Charnley, S. B. 1991, ApJ, 369, 147

Mizuno, A., Fukui, Y., Nozawa, S., \& Takano, T. 1990, ApJ, 356, 184

Mundy, L. G., Wootten, H. A., \& Wilking, B. A. 1990, ApJ, 352, 159

Mundy, L. G., Wootten, H. A., Wilking, B. A., Blake, G. A., \& Sargent, A. I. 1992, ApJ, 385, 306

Mundy, L. G., et al. 1994, in preparation

Neufeld, D. A., \& Dalgarno, A. 1989, ApJ, 340, 869

Ohishi, M., Irvine, W. M., \& Kaifu, N. 1992, in IAU, Symp. 150, The Astrochemistry of Cosmic Phenomena, ed. P. D. Singh (Dordrecht : Kluwer), 171

Phillips, T. G., van Dishoeck, E. F., \& Keene, J. 1992, ApJ, 399, 533

Poynter, R. L., \& Pickett, H. M. 1992, NASA JPL Publ. 80-23, Rev. 3

Raga, A. C., \& Cabrit, S. 1993, A\&A, 278, 267

Schilke, P., Walmsley, C. M., Pineau des Forêts, G., Roueff, E., Flower, D. R., \& Guilloteau, S. 1992, A\&A, 256, 595

Sutton, E. C., Jaminet, P. A., Danchi, W. C., \& Blake, G. A. 1991, ApJS, 77, 255

Swade, D. A. 1989, ApJ, 345, 828 


\section{VAN DISHOECK ET AL.}

Walker, C. K., Lada, C. H., Young, E. T., Maloney, P. R., \& Wilking, B. A. 1986, ApJ, 309, L47

Terebey, S., Vogel, S. N., \& Myers, P. C. 1992, ApJ, 390, 181

Tielens, A. G. G. M. 1989, in IAU Symp. 135, Interstellar, Dust, ed. L. J.

Allamandola \& A. G. G. M. Tielens (Dordrecht: Kluwer), 239

1 Turner, B. E. 1988, in Galactic and Extragalactic Radio Astronomy, ed. G. L. Verschuur \& K. I. Kellerman (Berlin: Springer), 154

.1990, ApJ, 362, L29

InI - 1991, ApJS, 76, 617

I. van Dishoeck, E. F., Blake, G. A., Draine, B. T., \& Lunine, J. I. 1993a, in Protostars and Planets III, ed. E. H. Levy \& J. Lunine (Tucson: Univ. Arizona Press), 163

van Dishoeck, E. F., Jansen, D. J., \& Phillips, T. G. 1993b, A\&A, 279, 54

Walker, C. K., Carlstrom, J. E., \& Bieging, J. H. 1993, ApJ, 402, 655

Walker, C. K., Carlstrom, J. E., Bieging, J. H., Lada, C. H., \& Young, E. T. 1990, ApJ, 364, 173

Walker, C. K., Lada, C. H., Young, E. T., \& Margulis, M. 1988, ApJ, 332, 335

Walmsley, C. M. 1987, in Physical Processes in Interstellar Clouds, ed. G. Morfill \& M. S. Scholer (Dordrecht: Reidel), 161

Walmsley, C. M., Hermsen, W., Henkel, C., Mauersberger, R., \& Wilson, T. L. 1987, A\&A, 172, 311

Walmsley, C. M., \& Schilke, P. 1993, in Dust and Chemistry, ed. T. J. Millar \& D. A. Williams (Dordrecht: Kluwer), 37

Wilking, B. A., \& Claussen, M. J. 1987, ApJ, 320, L133

Wootten, A. 1989, ApJ, 337, 858

Wootten, A. \& Loren, R. B. 1987, ApJ, 317, 220

Ziurys, L. M., Snell, R. L., \& Dickman, R. L. 1989, ApJ, 341, 857 